\title{
Model and Analytic Processes for Export License Assessments
}

$\begin{array}{ll}\text { S Thompson } & \text { PD Whitney } \\ \text { MR Weimar } & \text { TW Wood } \\ \text { DS Daly } & \text { AJ Brothers } \\ \text { AP Sanfilippo } & \text { D Cook }\end{array}$

L Holder

September 2011

Pacific Northwest

NATIONAL LABORATORY

Proudly Operated by Battelle Since 1965 


\title{
DISCLAIMER
}

This report was prepared as an account of work sponsored by an agency of the United States Government. Neither the United States Government nor any agency thereof, nor Battelle Memorial Institute, nor any of their employees, makes any warranty, express or implied, or assumes any legal liability or responsibility for the accuracy, completeness, or usefulness of any information, apparatus, product, or process disclosed, or represents that its use would not infringe privately owned rights. Reference herein to any specific commercial product, process, or service by trade name, trademark, manufacturer, or otherwise does not necessarily constitute or imply its endorsement, recommendation, or favoring by the United States Government or any agency thereof, or Battelle Memorial Institute. The views and opinions of authors expressed herein do not necessarily state or reflect those of the United States Government or any agency thereof.

\author{
PACIFIC NORTHWEST NATIONAL LABORATORY \\ operated by \\ BATTELLE \\ for the \\ UNITED STATES DEPARTMENT OF ENERGY \\ under Contract DE-AC05-76RL01830
}

Printed in the United States of America

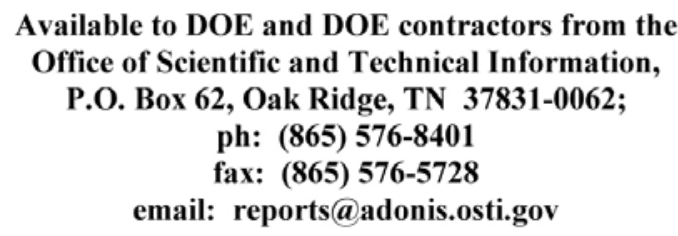

Available to the public from the National Technical Information Service

5301 Shawnee Rd., Alexandria, VA 22312 ph: (800) 553-NTIS (6847)

email: orders@ntis.gov <http://www.ntis.gov/about/form.aspx>

Online ordering: http://www.ntis.gov 


\title{
Model Analytic Processes for Export License Assessments
}

\author{
S Thompson \\ PD Whitney \\ MR Weimar \\ TW Wood \\ DS Daly \\ AP Sanfilippo \\ AJ Brothers \\ L Holder \\ D Cook
}

September 2011

Prepared for

the U.S. Department of Energy

under Contract DE-AC05-76RL01830

Pacific Northwest National Laboratory

Richland, Washington 99352 



\section{Summary}

This report represents the U.S. Department of Energy Office of Nonproliferation Research and Development (NA-22) Simulations, Algorithms and Modeling (SAM) Program's first effort to identify and frame analytical methods and tools to aid export control professionals in effectively predicting proliferation intent—a complex, multi-step and multi-agency process.

The report focuses on analytical modeling methodologies that alone, or combined, may improve the proliferation export control license approval process. It is a follow-up to an earlier paper describing information sources and environments related to international nuclear technology transfer. This report describes the decision criteria used to evaluate modeling techniques and tools to determine which approaches will be investigated during the final 2 years of the project. The report also details the motivation for why new modeling techniques and tools are needed.

The analytical modeling methodologies will enable analysts to evaluate the information environment for relevance to detecting proliferation intent, with specific focus on assessing risks associated with transferring dual-use technologies. Dual-use technologies can be used in both weapons and commercial enterprises.

A decision-framework was developed to evaluate which of the different analytical modeling methodologies would be most appropriate conditional on the uniqueness of the approach, data availability, laboratory capabilities, relevance to NA-22 and Office of Arms Control and Nonproliferation (NA-24) research needs and the impact if successful.

Modeling methodologies were divided into whether they could help micro-level assessments (e.g., help improve individual license assessments) or macro-level assessment. Macro-level assessment focuses on suppliers, technology, consumers, economies, and proliferation context. Macro-level assessment technologies scored higher in the area of uniqueness because less work has been done at the macro level. An approach to developing testable hypotheses for the macro-level assessment methodologies is provided.

The outcome of this works suggests that we should develop a Bayes Net for micro-level analysis and continue to focus on Bayes Net, System Dynamics and Economic Input/Output models for assessing

macro-level problems. Simultaneously, we need to develop metrics for assessing intent in export control, including the risks and consequences associated with all aspects of export control. 



\section{Abbreviations and Acronyms}

\begin{tabular}{|c|c|}
\hline $\mathrm{ACE}$ & agent-based computational economy \\
\hline $\mathrm{ACH}$ & Analysis of Competing Hypotheses \\
\hline BIS & Bureau of Industry and Security \\
\hline CA & Content Analysis \\
\hline CGE & computable general equilibrium \\
\hline DHS & Department of Homeland Security \\
\hline DOE & U.S. Department of Energy \\
\hline FY & fiscal year \\
\hline GDP & Gross Domestic Product \\
\hline $\mathrm{HG}$ & Hunter Gatherer \\
\hline HTS & harmonized tariff schedule \\
\hline NA-22 & Office of Nonproliferation Research and Development \\
\hline NA-24 & Office of Arms Control and Nonproliferation \\
\hline NSG & Nuclear Suppliers Group \\
\hline PNNL & Pacific Northwest National Laboratory's \\
\hline R\&D & research and development \\
\hline SAM & Simulations, Algorithms and Modeling (Program) \\
\hline SCL & sensitive country list \\
\hline $\mathrm{SD}$ & System Dynamics \\
\hline SITC & Standardized Industrialized Trade Classification \\
\hline TSG & triggered spark gap \\
\hline UN & United Nations \\
\hline VIMS & Violent Intent Modeling System \\
\hline WMD & weapons of mass destruction \\
\hline WSU & Washington State University \\
\hline WWW & World Wide Web \\
\hline
\end{tabular}




\section{Contents}

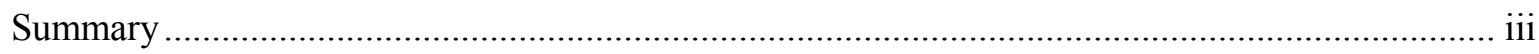

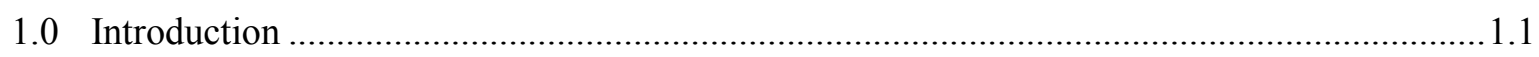

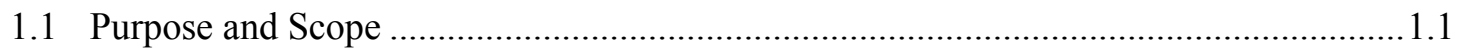

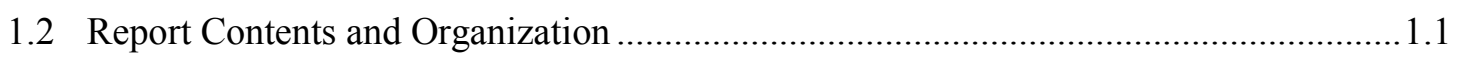

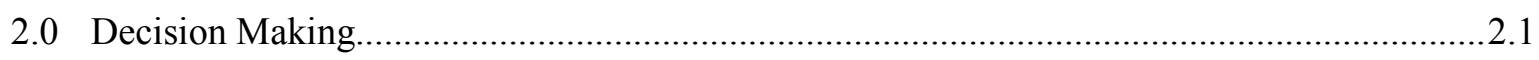

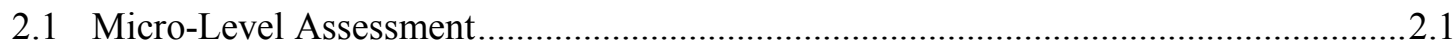

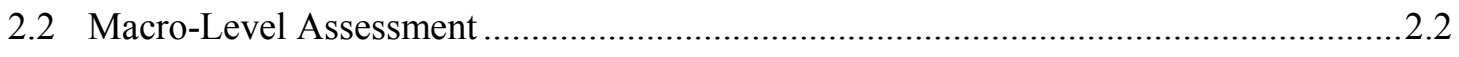

3.0 Motivation for Improved Analytical Techniques for Export Control.......................................

4.0 Modeling and Methodology Goals ................................................................................. 4.1

4.1 Support for Export License Assessments ................................................................. 4.1

4.2 Verification, Validation, and Calibration ................................................................... 4.2

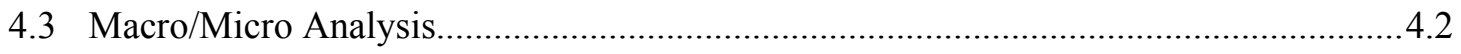

4.4 Consistency with Analysis Practice ............................................................................. 4.3

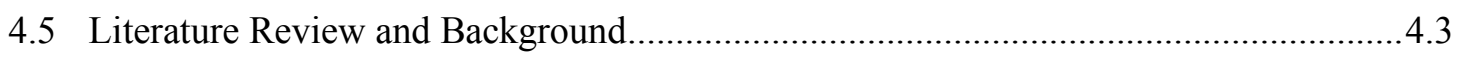

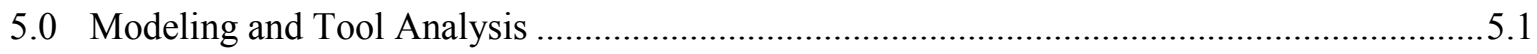

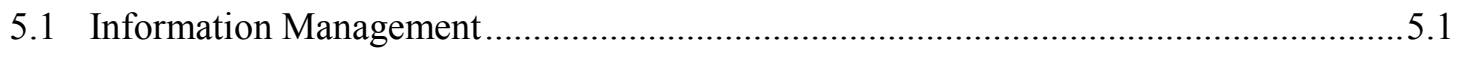

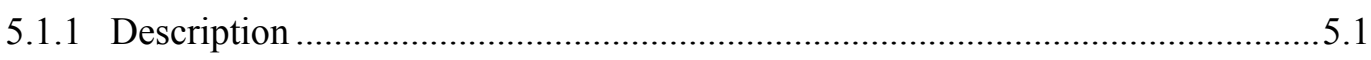

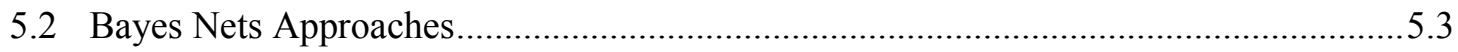

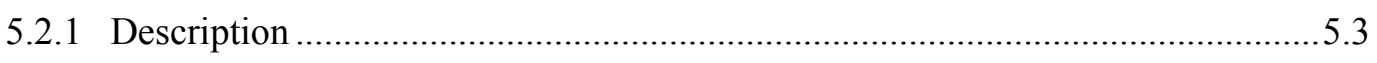

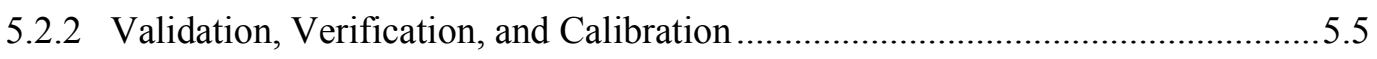

5.2.3 Application to Export Control License Analysis ...............................................5.6

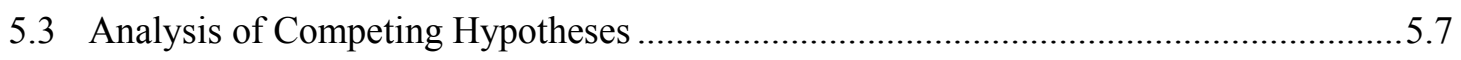

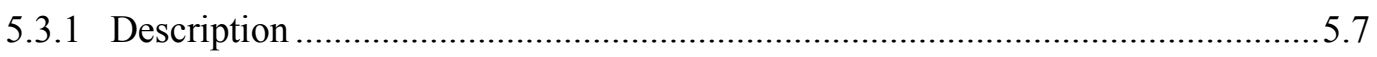

5.3.2 Validation, Verification, and Calibration ........................................................ 5.7

5.3.3 Application to Export Control License Analysis ..............................................5.8

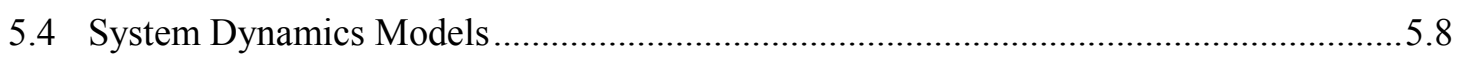

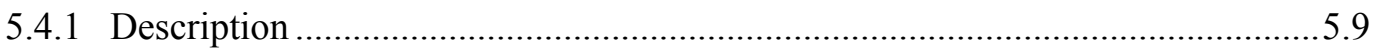

5.4.2 Causal Diagrams ..................................................................................... 5.9

5.4.3 Verification, Validation, and Calibration ....................................................... 5.10

5.4.4 Application to Export Control License Analysis .............................................5.10

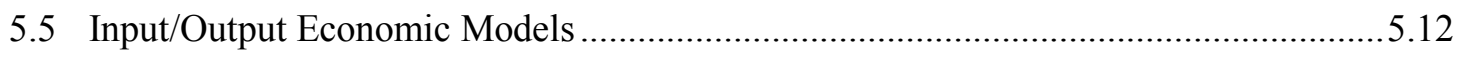

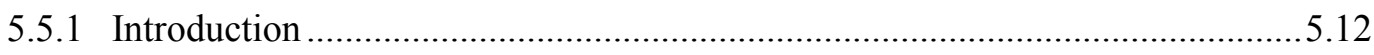

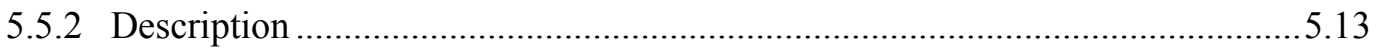

5.5.3 Macro/Micro Environment Applications .......................................................5.15

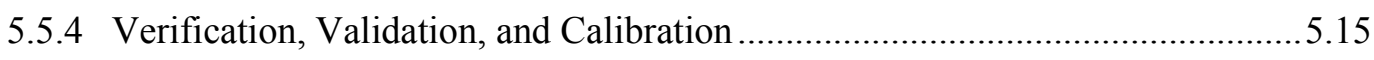

5.5.5 Support for Export License Assessment and Associated Analysis .....................5.16 


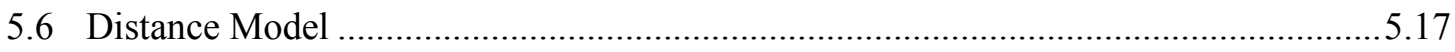

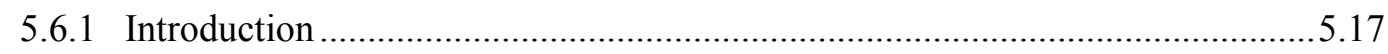

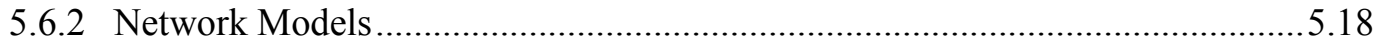

5.6.3 Measures of Technology Stock or Capability .................................................5.21

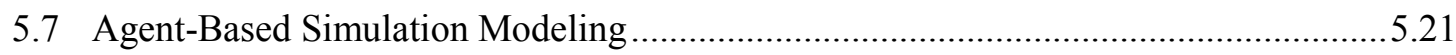

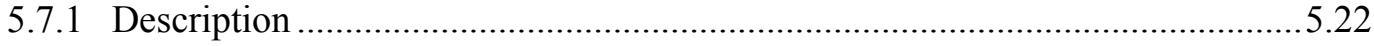

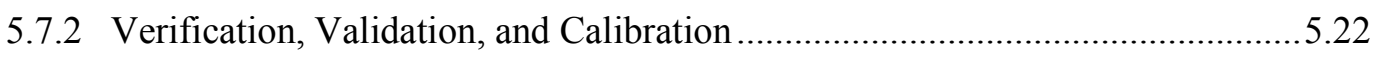

5.7.3 Application to Export Control License Analysis .............................................5.23

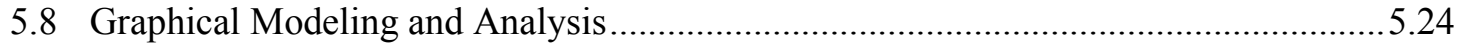

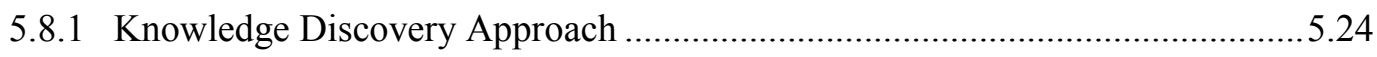

5.8.2 Evaluation of the Data-Mining Algorithm .......................................................25

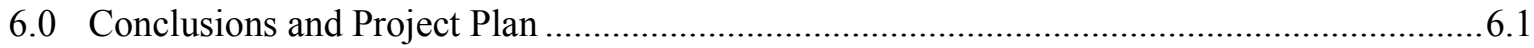

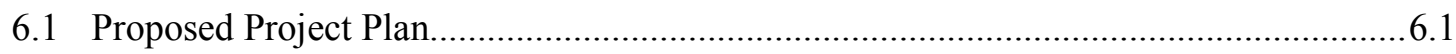

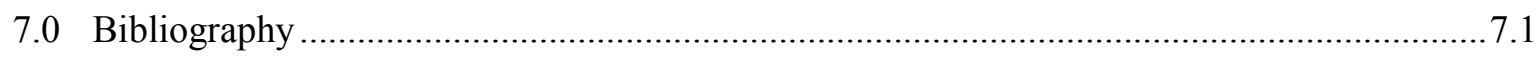

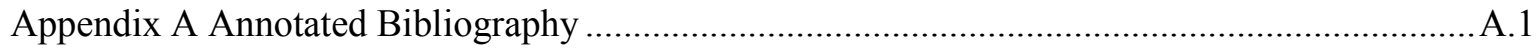




\section{Figures}

Figure 5.1. Semantically Driven Navigation in Hunter-Gatherer .................................................2

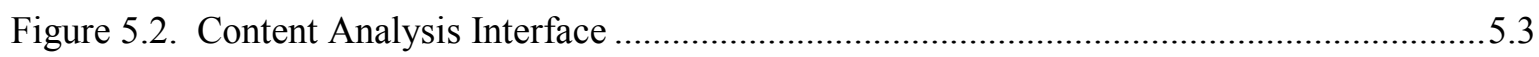

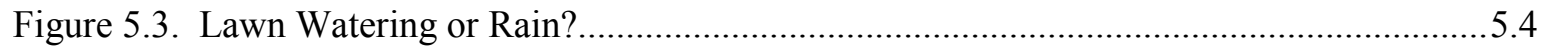

Figure 5.4. Network Given My Lawn Is Wet and My Neighbor's Lawn Is Dry ..........................5.4

Figure 5.5. Bayes Net Representation of Model Assessing Likelihood of a Group Split..............5.5

Figure 5.6. A Candidate Bayes Net Model for Supporting Analysis of License Applications.......5.6

Figure 5.7. Example ACH for Export Control Example.............................................................5.8

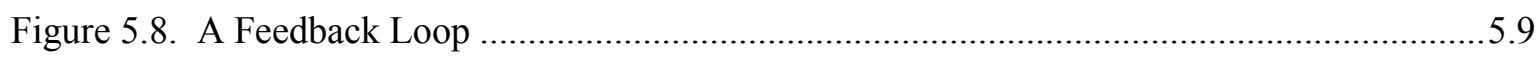

Figure 5.9. Compensation Loop Between Sleep and Tiredness..............................................5.10

Figure 5.10. System Dynamics Representation of Bank Balance and Interest Paid.....................5.10

Figure 5.11. Example of Unstable Causal Loop ........................................................................5.11

Figure 5.12. Tertrais's System Dynamics Model of Pakistan....................................................5.12

Figure 5.13. Representation of Transactions Table for Economy............................................5.13

Figure 5.14. Technical Coefficients Table of the Representative Economy................................5.14

Figure 5.15. Network for Uranium Transfer (Morstein et al. 2000) ...........................................5.18

Figure 5.16. Scheme for Network Definition .......................................................................19

Figure 5.17. Numbers of Steps in Shortest Paths from NSG to SCL.........................................5.19

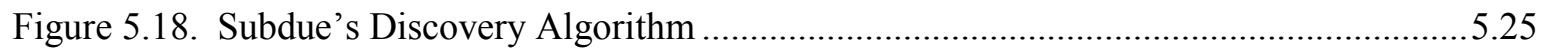

Figure 5.19. An Example of Subdue's Substructure Discovery Capability..................................5.26

\section{Tables}

Table 2.1. Summary of Model Decision Process for Predicting Intent Project ...........................2.2

Table 3.1. Excerpts from U.S. Department of Commerce's Bureau of Industry and Security (BIS) Major WMD and Missile Proliferation Cases with Key Issues*

Table 4.1. Critical Components of Analysis Practice. The characteristics of successful strategies and common roadblocks are documented in both the intelligence analysis literature and in the business forecasting literature. This table summarizes strategies from both technical communities...... 


\subsection{Introduction}

This report documents Pacific Northwest National Laboratory's (PNNL's) first endeavor to identify, frame, and develop analytical methods and tools to aid export control professionals in their efforts to effectively predict an entity's proliferation intent - a complex, multi-step and multi-agency process. PNNL performed the analysis for the U.S. Department of Energy (DOE) Office of Nonproliferation Research and Development (NA-22) Simulations, Algorithms and Modeling (SAM) Program. The overall goals of the project are to derive rules and identify flexible analysis tools to improve analytical detection and prediction of high risk export control licenses; adapt analytical techniques for model-driven analysis of export control scenarios; and provide decision makers with improved confidence levels and resource allocation guidance.

An earlier report of a companion working paper examined the assessment process and the information used by DOE to assess prospective international transfers of nuclear technology. The earlier paper focused on the information environmental currently relevant to Office of Arms Control and Nonproliferation (NA-24) domains, including the data sources, their structures and relationships.

\subsection{Purpose and Scope}

This follow-on report provides an overview of relevant criteria and characteristics for dual-use export license assessment modeling and methodology, with special focus on the intent of the transaction, and it describes options for the modeling and methodology that can support understanding and incorporating intent in export license assessment. The intent could be at any level in the supply chain, i.e., the buyer, seller, end-user, business, or country. This report initiates the model development tasks. The models and tools evaluated include Violent Intent Modeling System, Bayes Nets, System Dynamics, Economic Input/Output, Distance and Agent-based Simulation models. In addition, graphical modeling and analysis was assessed. These models can be informed by observables and data identified by Wood et al. (2008).

When examining a proposed dual-use export transaction, and determining whether an export license should be granted, an analyst faces the fundamental challenge of identifying and then sifting the wealth of relevant direct and contextual information, which will indicate whether the transaction is for a legitimate commercial use or not. Dual-use exports are technologies that can be used in either nuclear weapons development or in commercial production. A critical challenge to export control analysis is collecting relevant data and identifying actionable evidence. The purpose of this project was to provide assistance in effectively using this information for export license assessment through the development of tools and methods that would inform analysts and other decision makers at the micro (individual license assessment) and the macro (policy) level. The work was completed by a team from PNNL and Washington State University (WSU). The report focuses on determining which tools and methodologies should be carried forward into the next 2 years of work based a decision-making framework.

\subsection{Report Contents and Organization}

The ensuing sections of this report describe the decision-making framework, motivation for improved analytical techniques, modeling methodology goals and approach, modeling and tool analyses, and lastly conclusions. An annotated bibliography is contained in an appendix following the references section. 
At the beginning of the project, a decision-making structure was developed to assess at which levels the project could provide the most benefit given the number of methods, tools, and data availability. The framework was used to focus on the methods most likely to provide valuable export license assessment that was not already available elsewhere. The decision-making framework also included the plan to undertake the work that would eventually lead to the down-selected methods and/or tools.

The next section details the motivations for improved analytical tools. The section outlines DOE needs in terms of improved license assessment tools to determine whether an export license should be approved and tools to inform policymakers. It details the needs by illustrating a particular case involving triggered spark gaps and identifying a partial list of other dual-use cases. The case list helped identify which areas of tools and modeling methodologies could provide additional information for an assessment.

In the section on modeling and tool methodology goals, the requirements for supporting export license assessments are described. The section describes the approach to measuring how good a tool or model may be by testing it through verification, validation, and calibration; micro- versus macro-level modeling requirements; and the requirements of the models to be consistent with good analysis and forecasting. Lastly, the section details the literature review approach used to identify the different models, techniques, and requirements for improving the export license assessment. The information categories within the literature review include technical papers on behavioral factors, articles and presentations on the mechanics of license applications and export assessments, discussions of analytic and modeling methodologies, and case studies and analyses of organizations and individuals involved in the proliferation of weapons of mass destruction (WMD). Selected papers are described briefly in the appendix.

The last section of the report describes the models and tools analyzed. Each subsection describes a model or tool and how it would help meet assessment needs. For new models, the approach to verification, validation, and calibration also are discussed. 


\subsection{Decision Making}

To prioritize the project's modeling research and development (R\&D) for fiscal year 2009 (FY09) and FY10, the PNNL team developed a decision-making framework to decide where the highest added value would be in terms of new modeling techniques and tools. PNNL used the decision-making framework to update the original project work plan, based primarily on eight criteria, which are summarized in Table 1. The criteria were identified as being useful for evaluating proliferation intent problems and focusing research directions. The criteria include the following:

- Uniqueness: The proposed research does not overlap with current known research and operational work at laboratories and organizations. The primary concern is to identify new modeling techniques or tools that have a high potential contribution to dual-use export license assessment.

- Potential relevance to NA-22: The proposed research requires further R\&D and has a strong connection to proliferation issues.

- Potential relevance to NA-24: Successful development of the modeling technique or tool contributes to the operational capabilities of the NA-24 office with high potential for success.

- Capability in modeling approaches: Does PNNL have experts or collaborators with expertise in the required modeling area?

- Availability of data: This includes issues of classification of, ease of access to, and availability of surrogate data.

- Generalization to similar problems: The modeling frameworks can be applied to other proliferation problems.

- Value if successful: Successful development of modeling techniques or tools for export license assessment will result in changes to R\&D priorities or operational activities.

- Supports Intent Assessment: The modeling results will affect or contribute to the assessment of proliferation intent.

Exploration of a variety of modeling methodologies through a literature review derived a number of different pathways that can serve as the focus for the remaining 2 years of the project. Many modeling techniques and tools appear to be useful in addressing issues associated with export license assessment and determining potential proliferation intent. Assessment of proliferation intent focuses on weighing the proliferation risk against the credibility of the exported technology's dual use in the commercial sector. In this report, proliferation intent problems are classified as either micro- or macro-level assessments, although many assessments will include components at multiple levels.

\subsection{Micro-Level Assessment}

Micro-level assessments focus on improving the analysis at an individual license application level. Example techniques include methods for organizing and automating individual assessment processes, or development of analysis techniques focused on an individual seller or buyer. Three significant challenges arise from the micro-level assessment. They include the diversity in details contained within an 
individual license application, a high level of credibility in current license reviews as thousands of license requests are reviewed by experts every year, and the lack of data due to data access restrictions.

Table 2.1. Summary of Model Decision Process for Predicting Intent Project

\begin{tabular}{lcc}
\hline & $\begin{array}{c}\text { Micro-Level } \\
\text { Assessment }\end{array}$ & $\begin{array}{c}\text { Macro-Level Assessment (Country, } \\
\text { Industry and Commodity) }\end{array}$ \\
\hline $\begin{array}{l}\text { Uniqueness } \\
\begin{array}{l}\text { Potential relevance to NA-22 } \\
\text { (R\&D focus) }\end{array}\end{array}$ & Very low & High \\
$\begin{array}{l}\text { Potential relevance to NA-24 } \\
\text { (operational focus) }\end{array}$ & High \\
$\begin{array}{l}\text { Capability in modeling approaches } \\
\text { Availability of data }\end{array}$ & High & Very High \\
$\begin{array}{l}\text { Generalization to similar problems } \\
\text { Value if successful }\end{array}$ & Neutral & High \\
Supports intent assessment & High, but classified & High, much open source \\
& Low & High \\
& High & High \\
\hline
\end{tabular}

\subsection{Macro-Level Assessment}

Macro-level assessment incorporates the larger proliferation picture, focusing on one or more components listed below:

- Suppliers: countries or companies providing technology

- Technology: specific items or commodities, or groupings of items

- Consumers: countries and/or companies interested in acquiring technology

- Economy: the social system focused on production, distribution, and use of technology, both dual use and proliferation only. The level of granularity can vary from company to country, region, or worldwide based on the available data.

- Proliferation context: organizational framework describing the entire proliferation cycle. This framework could initiate with the FreezeFrame model (Willingham 2011), but be extended to include advances in technology.

Areas of concern for the export of dual-use technologies can emerge at the technology level, the industry level, company, region, or country level. These more aggregated analyses are of interest to the larger non-proliferation community, are more tractable in terms of modeling and data availability, and have fewer existing capabilities compared to capabilities at the individual case level.

Critical components required for analysis of macro-level questions include the following:

- A set $\mathrm{H}_{\mathrm{e}}$ of hypotheses (ideas, options) for how the technology would/could be used in the dual-use economy. In an export case, the dual use is required to be specified. In an interdiction case, there may not be any hypotheses that describe the dual use of the item. In some high-level assessments, the list of hypotheses is undetermined and needs to be "estimated."

- A similar set of hypotheses $\mathrm{H}_{\mathrm{w}}$ about how the technology might be used in the proliferation economy. This may also need to be estimated. 
- A metric $\varepsilon(\mathrm{S}, \mathrm{T}, \mathrm{C}, \mathrm{E})$ that measures the degree of credibility of $\mathrm{H}_{\mathrm{e}}$ or some important subset of it.

- A metric $\Psi(\mathrm{S}, \mathrm{T}, \mathrm{C}, \mathrm{P})$ that measures the degree of credibility of $\mathrm{H}_{\mathrm{w}}$ or some important subset of it.

- A set of constraints that express "axioms" with respect to reasonable behavior for the functions $\varepsilon$ and $\Psi$. For example, the risk due to some technologies is a function of complementary technologies as well. This constraint set could also be used to ensure that the assessments are reasonably free of political bias.

- A framework within which to integrate and compare $\varepsilon$ and $\Psi$. Bayes Nets, or Analysis of Competing Hypotheses $(\mathrm{ACH})$ are initial possibilities.

Analysis will also require investigation into the risk and consequences of the decision-making process. For example, the risk of falsely granting approval may improve an adversary's nuclear proliferation capabilities. Falsely failing to approve a product transfer may affect the commercial abilities of a company. 



\subsection{Motivation for Improved Analytical Techniques for Export Control}

The motivation for conducting this research project is twofold: micro-level assessment is needed to improve the process of determining whether individual licenses should be approved, and macro-level assessment is needed to support the prioritization of license application policy. The micro-level assessment focuses on the license application approval process. The project does not address post-license approval activities: enforcement, interdiction, prosecution, and sanctions. ${ }^{1}$ In the license application process, the license is evaluated against the potential for the items to be used illegally.

In terms of macro-level assessment, this project aims to provide an enhanced analytical framework for a variety of decision-making tasks. These tasks include assessment of the proliferation potential of a country based on trade, development of a process for prioritization of dual-use items that takes into account the industrial growth of the dual-use rationale, and assessment of the proliferation state of a country based on trade.

The export control license process is described in a previous report, Information Environment for DOE Nuclear Supply and Export Assessment (Wood et al. 2008). A number of proliferation cases (Table 3.1) in the public press call out the need to improve the export control process. One example is the case of Asher Karni, reported on Frontline, ${ }^{2}$ in the international press ${ }^{3}$, and by academia. ${ }^{4}$ The story behind Asher Karni demonstrates areas for improvement in the export control license process. The activities of the Asher Karni case and other identified gaps in the export control process are summarized below. The example provides the motivation for many of the modeling techniques attempting to predict intent and demonstrates how structured analytical techniques may improve the assessment process.

Asher Karni was arrested in 2004 and sentenced in $2005^{5}$ for attempting to purchase 200 triggered spark gaps. Triggered spark gaps (TSGs) are considered a dual-use item. For example, TSGs can be used as 1) a component of lithotripters, a piece of medical equipment used to treat kidney stones, and 2) detonators for nuclear weapons. The Nuclear Suppliers Group ${ }^{6}$ restricts export of dual-use items in cases of high risk of proliferation use. Export of TSGs is restricted for a subset of countries with high proliferation risk.

\footnotetext{
${ }^{1}$ Presentation: Bauer S and A Wetter. 2007. Approaches to Enhanced Prosecution and Sanctions for Dual-use Export control Violations. SIPRI. Bucharest, Bulgaria, March 6.

${ }^{2}$ Frontline three part series, available at www.pbs.org/frontlineworld/stories/nuclear/part1.html

${ }^{3} \mathrm{http}$ ://www.hindu.com/2005/04/10/stories/2005041001231200.htm, and

4 www.isis-online.org/publications/southafrica/asherkarni.html, and

5 http://www.bis.doc.gov/news/2005/karniasher sen pre.pdf

6 www.nuclearsuppliersgroup.org
} 
Table 3.1. Excerpts from U.S. Department of Commerce's Bureau of Industry and Security (BIS) Major WMD and Missile Proliferation Cases with Key Issues*

\begin{tabular}{|c|c|c|}
\hline $\begin{array}{l}\text { Case } \\
\text { ID }\end{array}$ & $\begin{array}{l}\text { Modus } \\
\text { operandi }\end{array}$ & $\begin{array}{l}\text { BIS Major WMD and Missile Proliferation Cases. (Citation: BIS Export } \\
\text { Enforcement. February 2008. Major Cases List. U.S. Department of Commerce: } \\
\text { 15) }\end{array}$ \\
\hline 1 & $\begin{array}{l}\text { Falsified } \\
\text { application }\end{array}$ & $\begin{array}{l}\text { Nuclear Detonators to Pakistan: August } 1,2006 \ldots \text { purchase and export ... spark } \\
\text { gaps ... falsely indicated that the goods were intended for medical use }\end{array}$ \\
\hline 2 & $\begin{array}{l}\text { Falsified } \\
\text { application }\end{array}$ & $\begin{array}{l}\text { Industrial Furnace to China: October } 4,2006 \ldots \text { falsely stating in export } \\
\text { documents that the furnace did not require an export license }\end{array}$ \\
\hline 3 & $\begin{array}{l}\text { No export } \\
\text { license }\end{array}$ & $\begin{array}{l}\text { Nickel Powder to Taiwan: October } 11,2007 \ldots \text { making false statements related to } \\
\text { the export of nickel powder without an export license. }\end{array}$ \\
\hline 4 & $\begin{array}{l}\text { Falsified } \\
\text { application }\end{array}$ & $\begin{array}{l}\text { Graphite Products to the United Arab Emirates: October } 4,2007 \ldots \text { falsify } \\
\text { documents related to the graphite shipment and then attempted to mislead federal } \\
\text { investigators when questioned about the shipment and the documents. }\end{array}$ \\
\hline 5 & $\begin{array}{l}\text { No export } \\
\text { license }\end{array}$ & $\begin{array}{l}\text { Carbon-Carbon Industrial Manufacturing Equipment to Missile Laboratory in } \\
\text { India: November } 18,2005 \ldots \text { unlicensed export to India of equipment used to } \\
\text { manufacture carbon-carbon components }\end{array}$ \\
\hline 6 & $\begin{array}{l}\text { No export } \\
\text { license? }\end{array}$ & $\begin{array}{l}\text { Controlled Items to Ballistic Missile Facility in Iran: September } 2005 \ldots \text { illegally } \\
\text { export goods to Iran via the United Arab Emirates (UAE). }\end{array}$ \\
\hline 7 & $\begin{array}{l}\text { No export } \\
\text { license }\end{array}$ & $\begin{array}{l}\text { Chemical and Biological Weapons Controlled Toxins to Syria: August 5, } 2005 \\
\ldots \text { unlicensed exports of virus toxins to Syria ... conspiracy, illegal exports, } \\
\text { smuggling, false statements, aiding and abetting, and anti-boycott offenses. }\end{array}$ \\
\hline 8 & $\begin{array}{l}\text { No export } \\
\text { license }\end{array}$ & $\begin{array}{l}\text { Thermal Insulation Blankets to China: May 17, } 2005 \ldots \text { attempted export of } \\
\text { satellite/missile insulation blankets to the Chinese Academy of Space Technology } \\
\text {... rejected Valtex's application for an export license for these items. }\end{array}$ \\
\hline 9 & $\begin{array}{l}\text { No export } \\
\text { license }\end{array}$ & $\begin{array}{l}\text { Digital Oscilloscopes Controlled for Nuclear Nonproliferation Reasons to } \\
\text { Israel: March 21, } 2005 \ldots \text { exporting digital oscilloscopes to Israel without a BIS } \\
\text { license. }\end{array}$ \\
\hline 10 & $\begin{array}{l}\text { Falsified } \\
\text { application }\end{array}$ & $\begin{array}{l}\text { Computer Chips with Guidance System Applications to China: October 6, } 2004 \\
\ldots \text { illegal export of low-noise amplifier chips ... falsely described the goods as } \\
\text { "transistors" in export documents }\end{array}$ \\
\hline 11 & $\begin{array}{l}\text { No export } \\
\text { license }\end{array}$ & $\begin{array}{l}\text { Pulse Generators to India: June } 6,2004 \ldots \text { illegally exporting pulse generators to } \\
\text { two entities in India without the required export licenses. }\end{array}$ \\
\hline 12 & $\begin{array}{l}\text { No export } \\
\text { license }\end{array}$ & $\begin{array}{l}\text { Bubonic Plague to Tanzania: March } 10,2004 \ldots \text { falsely reporting } \ldots .30 \text { vials of } \\
\text { bubonic plague bacteria that had been destroyed ... earlier exported a related set } \\
\ldots \text { without the required licenses. }\end{array}$ \\
\hline 13 & $\begin{array}{l}\text { Falsified } \\
\text { application? }\end{array}$ & $\begin{array}{l}\text { Biological Research Products to Indian Government Organizations on the } \\
\text { Entity List: December 28, } 2005 \ldots 36 \text { violations of the Export Administration } \\
\text { Regulations (EAR) involving the export of various life sciences research products }\end{array}$ \\
\hline 14 & $\begin{array}{l}\text { No export } \\
\text { license }\end{array}$ & $\begin{array}{l}\text { Exports of Chemical and Biological Weapons Controlled Chemicals to Multiple } \\
\text { Locations: August } 9,2005 \ldots 13 \text { exports of items controlled for chemical and } \\
\text { biological weapons reasons to various destinations without obtaining the required } \\
\text { export licenses. }\end{array}$ \\
\hline 15 & $\begin{array}{l}\text { No export } \\
\text { license }\end{array}$ & $\begin{array}{l}\text { Illegal Exports of Biotoxins to Canada: May 9, } 2005 \ldots \text { exports of biological } \\
\text { toxins to Canada that were made without obtaining required Department of } \\
\text { Commerce export licenses. }\end{array}$ \\
\hline
\end{tabular}

Karni contracted with a U.S. broker to purchase 200 TSGs for use in a South African hospital. Following export control rules, the broker required Karni to provide statement of the end use, as well as certification that the TSGs would not be shipped out of South Africa. Karni provided the justification, listing a hospital in South Africa. There were numerous discrepancies in the license request; many 
possibly attributable to errors in the application process. The broker filed incorrect licensing information on the license request, including the end user, and an incorrect Schedule B number that identifies dual-use equipment. The Schedule B number used in the application indicated no export license was required. Two hundred TSGs for hospital use is a very large order; large hospitals generally order roughly 5 to 6 per year. Alone, this information may not have been enough to attract attention and lead to denial of the export license.

Significant corollary information indicated this license application was a high risk. In 2003, Karni attempted to export TSGs from France. In conversation with the French manufacturer, Karni may have identified Pakistan instead South Africa as the end destination of the TSGs. The manufacturer in France relayed to Karni that this product is export controlled and would require a U.S. license.

In addition to providing improvements to the well-defined, focused application process to evaluate the proliferation risk posed by submitted export transactions, NA-24 and other government agencies are interested in problems that are abstracted or general versions of the export control intent assessment. These include 1) the structuring of bilateral nuclear cooperation agreements between the United States and other countries, 2) the evaluation of proposed multilateral control agreements for identified technology, and 3) the selection of technological content (lists of items) that should be subject to export control of various types.

All of these macro-level problems embody a kernel of "proliferation risk assessment" that involves evaluation of user intent, discriminating acceptable sets of users for given sets of technology from those that pose unacceptable proliferation risk. The analytic process (and models) used at the micro scale of individual license assessments cannot in general be simply replicated and aggregated for this set of more general applications ${ }^{7}$ - this analytic core of the process must be evaluated against more global metrics when large aggregates of technology, companies, and regions are concerned.

${ }^{7}$ The principal limitation is that the number of possible pathways (in economic and social space) through which proliferation can occur quickly increases as the number of actors and technological possibilities increases. 



\subsection{Modeling and Methodology Goals}

The overall intent and functional goal of modeling is to provide analytical support to the export license assessment process. Characteristics that should be considered in the development of predictive computational modeling include the following:

- support for export license assessments

- verification, validation, and calibration

- support for macro-level and micro analysis

- consistency with good analysis and forecasting practices.

We describe each of these in detail, as well as the approach to the literature review to identify modeling techniques and tools.

\subsection{Support for Export License Assessments}

Areas of support include addressing hypotheses of interest for license applications, identification of relevant data and information, integration of multiple information sources, and representation of known relevant processes.

Relevant hypotheses associated with a particular license application include the following:

- The proposed license application has a legitimate dual use as identified in the application.

- The proposed license application has a legitimate dual use but not as identified in the application (simple errors on the application).

- The proposed license application is at risk to be used directly for immediate proliferation use.

- The proposed license application is at high risk for proliferation through subsequent transfers.

The above hypotheses are focused on the micro level, addressing a single license application. At the macro level, this project will focus on development of country-level economic assessments that develop a profile of potential proliferation programs. These macro-level assessments can provide contextual information for micro-level assessments.

Relevant data for the export control challenge are described in the companion report by Wood et al. (2008). For the candidate modeling and analysis methodologies, the following criteria apply:

- The models can take as input the relevant data.

- The models can be incrementally updated by data.

- The models can incorporate uncertainty for inputs.

Relevant processes and modeling factors to consider include smuggling, theft, etc; loss, misplacement, misdirection of materials and information; explicit temporal characteristics; political climate of involved regions; and characteristics of the individuals and organizations involved in the proposed transaction. In particular, the modeling and analysis capabilities should be able to represent 
individuals' and organizations' histories with transactions and activities related with correct handling and/or mishandling of proliferating materials and information.

\subsection{Verification, Validation, and Calibration}

The dominant feature of this characteristic is the ability of a model or modeling approach to be validated or invalidated based on observations, empirical comparisons with competing models, and development of uncertainty bounds for assessments made. The terms have various uses in different disciplines. What we intend for these concepts are the following:

- verification - does the model behave as designed and according to specification?

- validation - is the model consistent with data (observations)?

- calibration -determining model performance characteristics (including precision and accuracy) through comparison of modeling and methodology outputs with data.

Finally, related to each of these concepts is the ability to address uncertainty. An important criterion is the ability to represent and propagate uncertainty within the modeling approach. The ability to relate output uncertainties with individual inputs or input models is a related critical capability for the modeling and analysis procedure to support.

\subsection{Macro/Micro Analysis}

There are multiple resolutions of interest for the modeling. The primary focus is at the individual/entity (license) level. Individuals are the basic unit of communication and transaction. The micro level refers to this level of a single proposed transaction. More aggregate resolution levels of interest include networks, organizations (companies), and countries that are associated with the individuals. The macro level of interest can be viewed as a set of multiple transactions. From an "input" perspective, this view would be used to provide contextual information relevant for assessing the relative likelihood of dual-use versus proliferation use. From the "output" perspective, a macro view could be used to monitor the state of proliferation. Finally, we hypothesize that the information across these levels will need to be combined to form an appropriate recommendation concerning a license application.

Macro information includes

- worldwide country-based economic information (trade figures, input/output tables, natural resources) diagnostic for legitimate use of dual-use technology.

- existing models of nuclear proliferation processes that will be adapted to provide indications of country-level proliferation intent.

Micro-level information includes candidate transaction and previous transactions elements included within the license request and assessments associated with the request. These include technology classification, buyer and seller evaluation, plausibility of proliferation use, and dual-use realism. 


\subsection{Consistency with Analysis Practice}

Any proposed modeling methodology should fit within the work structure of analysts. Largely motivated by ideas in Armstrong's Long-Range Forecasting (1985), and the Principles of Forecasting (2001), the elements of analysis practice are summarized in Table 4.1. Initial efforts will focus on mitigating bias, addressing anchoring, and valid evaluation of uncertainty. The same issues are described, using mostly the same language, in the intelligence analysis literature (Heuer 1999).

Table 4.1. Critical Components of Analysis Practice. The characteristics of successful strategies and common roadblocks are documented in both the intelligence analysis literature and in the business forecasting literature. This table summarizes strategies from both technical communities.

\begin{tabular}{ll}
\hline Successful strategies to take advantage of & Hurdles to overcome or avoid \\
\hline $\begin{array}{l}\text { Decomposition - taking larger problems into more } \\
\text { manageable sub-problems }\end{array}$ & $\begin{array}{l}\text { Bias - the human tendency to filter information to } \\
\text { support a desired conclusion. }\end{array}$ \\
$\begin{array}{l}\text { Amalgamation - combining distinct, eclectic predictors and } \\
\text { information sources to arrive at forecasts/conclusions. }\end{array}$ & $\begin{array}{l}\text { Anchoring - the human tendency to rely to fix } \\
\text { (anchor) on one trait or conclusion, to the extent of } \\
\text { using that conclusion as a filter for evidence. }\end{array}$ \\
$\begin{array}{l}\text { Retain past experience - calibrating against real-world } \\
\text { events and data. The conclusion from the business } \\
\text { forecasting literature is that 1) forecasts/conclusions need to uncertainty assessments tend to be } \\
\text { be clear cut and observable, and 2) previous predictions } \\
\text { (and the associated models and inputs) need to be saved. }\end{array}$ & $\begin{array}{l}\text { are data-driven, as opposed to opinion-driven. } \\
\text { andentes }\end{array}$ \\
\hline
\end{tabular}

\subsection{Literature Review and Background}

In formulating a modeling direction for the export control license application process, the team explored a large number of resources. The topics investigated encompassed the domain of proliferation assessment and the export control license approval process, as well as technical issues associated with potential modeling methodologies and tools. The appendix contains an annotated bibliography of the documents identified and reviewed. The literature review underpins the selection of modeling frameworks.

Documents reviewed by the team are grouped into the following five broad topics:

- information integration at multiple levels and various disciplines

- mathematical and computational models to predict intent. These documents span options for social and behavioral modeling, including agent-based modeling, System Dynamics, and Bayes Nets.

- social network modeling. These documents describe leveraging the information inherent in the relationship structures among entities.

- nuclear export control policies and policy issues

- case studies in proliferation assessment or export control. 



\subsection{Modeling and Tool Analysis}

Export licensing is a unique province of the international nuclear technology economy-a complicated world of geographically distributed entities interacting through markets and other structures to produce and exchange nuclear goods, services, and information. This economy is the end result of a process that involves nuclear technological evolution, governmental regulation, political history, and social organization, as well as geography and resource endowment, among other factors. These factors give context and content, and set the conditions and parameters in which the nuclear technology economy and the province of export licensing function. Getting a handle on the province of export licensing and this complex economy is critical to controlling the illegitimate proliferation of nuclear technology.

The next subsections include: information management, Bayes Net approaches, Analysis of Competing Hypotheses (ACH), input/output economic models, distance models, agent-based simulation models, and graphical modeling and analysis. The Information Management section discusses an already developed PNNL model that can be used to analyze large quantities of disparate data and potentially perceive the intent. The Graphical Modeling and Analysis section is the result of WSU's involvement in project; the content reports the results of their research. The remaining modeling and analysis approaches below are each described generally and also in the context of the micro and/or macro-level assessment process presented in the previous section.

\subsection{Information Management}

Improved information management and understanding is a critical need in the export control arena. As demonstrated by Wood et al. (2008), a panoply of export control data exists in a variety of databases, on diverse systems and classification levels, and spread throughout the World Wide Web. A critical challenge to export control analysis is collecting relevant data and identifying actionable evidence.

PNNL has developed a suite of information management and perception of intent capabilities under the Department of Homeland Security (DHS)-sponsored Violent Intent Modeling System (VIMS) project (Sanfilippo et al. 2009) that addresses critical data-collection and evidence-identification needs. The goal of VIMS is to help analysts assess the threat of violence posed by contentious radical groups and organizations. The VIMS information management and perception capabilities combine data collection with content extraction and analysis methods to identify evidence of violent intent VIMS capabilities can be easily tailored to satisfy intelligence tasks other than violent intent modeling. One project objective was to apply the VIMS information management and understanding capabilities to the WMD proliferation domain.

\subsubsection{Description}

The VIMS information management and understanding capabilities provide a web-enabled, semantically driven and visually interactive search environment that combines an information-extraction pipeline with the Alfresco (Alfresco ConMan Inc., Huntington Beach, CA) content-management environment and the SQL Server database (SQL Delight, Inc., Squirrel Notch, TN). It consists of two main components: Hunter Gatherer and Content Analysis. 
Hunter-Gatherer (HG) offers evidence gathering, exploration, and organization. It includes a ubiquitous data-capture tool allowing users to select relevant documents or document fragments within a variety of productivity tools such as web browsers (e.g., Internet Explorer), word processors (e.g., Microsoft Word), and email applications (e.g., Microsoft Outlook). The selected content is saved into the system content repository, alongside whatever provenance data are available, including annotations that the user may wish to add.

New data saved in the content repository are processed by an information-extraction pipeline, adding annotations about events of interest to the user with associated specifications of named entities (people, organizations, and locations), word domains, and dates (Sanfilippo et al. 2007, 2008). HG leverages these annotations to search, navigate, and organize data sets, as shown in Figure 5.1.

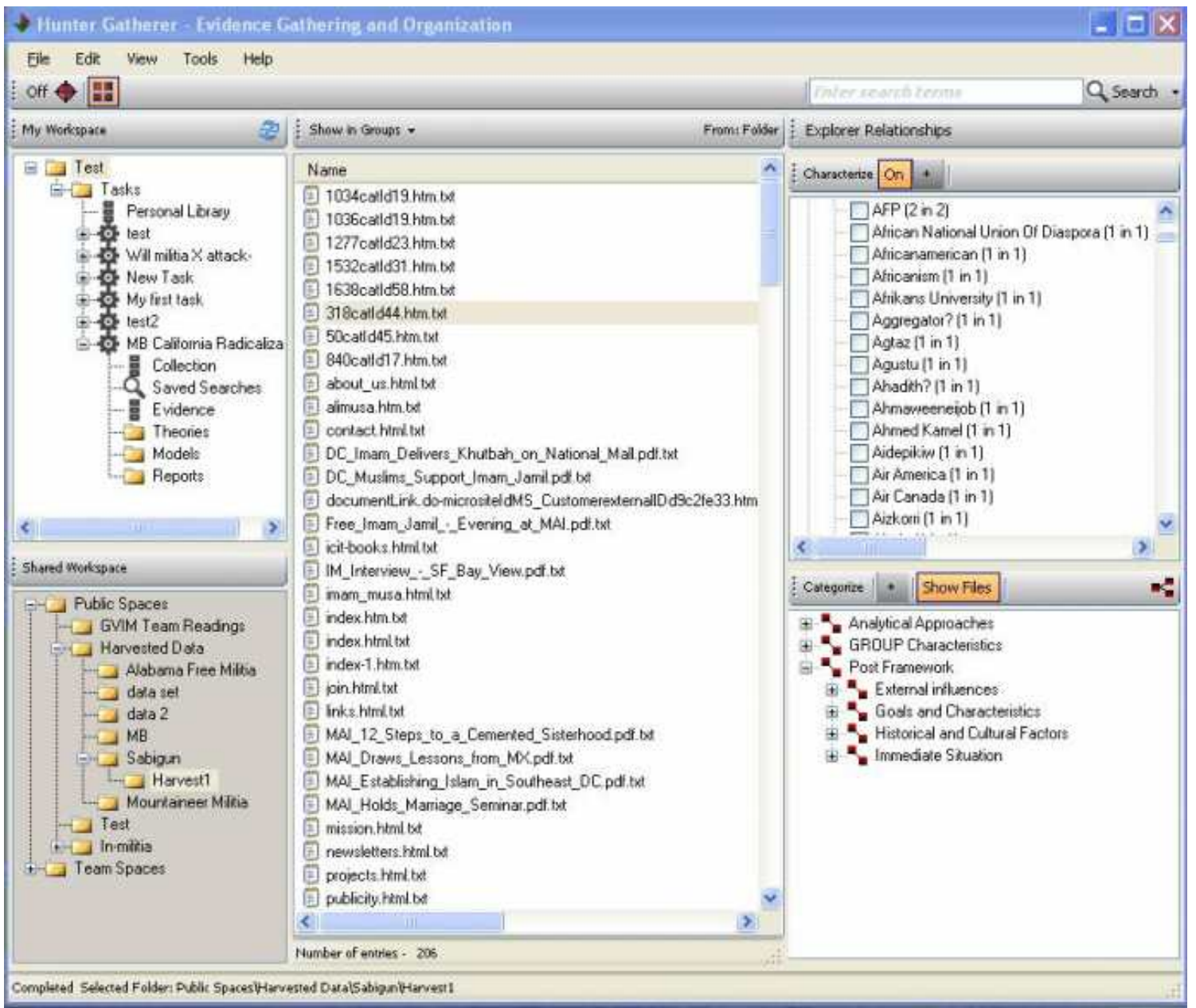

Figure 5.1. Semantically Driven Navigation in Hunter-Gatherer ${ }^{1}$

${ }^{1}$ The "Characterize" pane on the right side displays all the organizations, locations, and persons mentioned in the selected folder. Click on Explore Relationships to see people/organizations/location relationships for the entities of interest to you. The HG "Concentrator" reveals where these relationships are described in the underlying documents. You may also categorize your data: create/select a category, then drag and drop documents or evidence snippets onto the category tree. 
Content Analysis (CA) provides a web-enabled, semantically driven and visually interactive environment for event search and analysis, as shown in Figure 5.2. Currently, event detection covers about 4000 verbs, organized into a three-tiered hierarchy with a top layer of 31 event types branching into 120 event subtypes. This hierarchy can be easily tailored to specific analytical needs, such as the identification of group schism events. Nearly one-quarter of the event hierarchy is devoted to the automation of frame analysis to help identify the strategies that communication sources adopt to influence their target audiences (Sanfilippo et al. 2007, 2008).

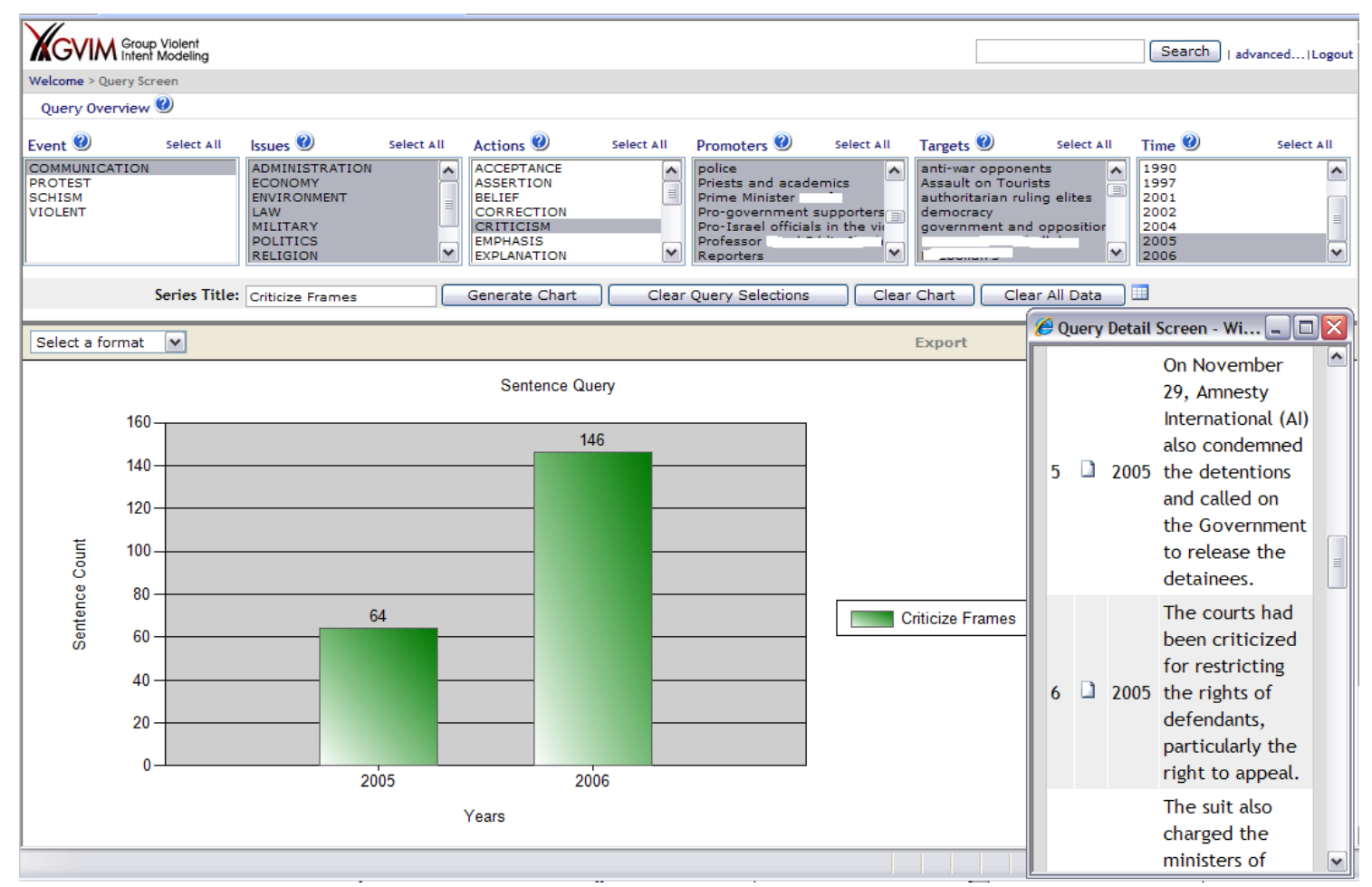

Figure 5.2. Content Analysis Interface

\subsection{Bayes Nets Approaches}

A Bayesian net is a graphical representation of relationships among variables. These networks are used to construct classifiers, fuse diverse information, and construct decision aids. For export license assessments, the variables of interest are related to assessing whether the export proposed in the license application has a legitimate dual use or has a high risk of proliferation use. There are numerous technical and tutorial references available for Bayes Nets (Jensen and Nielsen 2007; GeNIe 2008).

\subsubsection{Description}

Figure 5.3 and Figure 5.4 show common visual representations of Bayes Nets. The nodes in the visual representations are the variables. The arrows can be construed as indicating an "input" relationship. The precise meaning of the arrows in Bayes Nets is indicated below. In Figure 5.3 and Figure 5.4, the variables are discrete and take one of the values (e.g., the variable "My Lawn Watered" is either True or False; the variable "My Lawn State" takes either of the values "Wet" or "Dry"). The numeric values associated with each of the states are probability values. 
Mathematically, a Bayes Net is a concise representation of the joint distribution of a collection of random variables. The graph linking these variables is directed and acyclic. A parsimonious representation of the general joint distribution is obtained by the condition: variables with the same parent are conditionally independent given that parent.

The relationship among variables in Bayes Nets is probabilistic. Variables with no "parents" have probability values that are directly specified or inferred. Variables with parents have their conditional distribution given the parents specified.

Using Figure 5.3 and Figure 5.4 as examples demonstrates some of the potential inference capabilities. The network is shown twice: the first in an "unconstrained" state where the variable "My Lawn Watered" is shown with priors of 50-50, reflecting the concept that the lawn is watered every other day. The variable "Rains" has probability values set at 0.10 and 0.90 corresponding to a 10 percent chance of rain every day. The figure on the left represents the probability of lawn wetness without observing any information. The figure on the right corresponds to observing your wet lawn, and your neighbor's dry lawn, updating the original nodes to represent the increased probability your lawn was watered versus rain.

PNNL has also used Bayes Nets within VIMS to address a group's intent to engage in violent behavior. Assessment of intent is difficult and requires incorporation of diverse social and behavioral factors. Social sciences have made substantial contributions to the analysis of mechanisms associated with group violence, as illustrated by a wide body of available literature (e.g., Hafez 2003; Post et al. 2002). We have leveraged such literature to build quantitative models that encode social mechanisms underlying group violence.

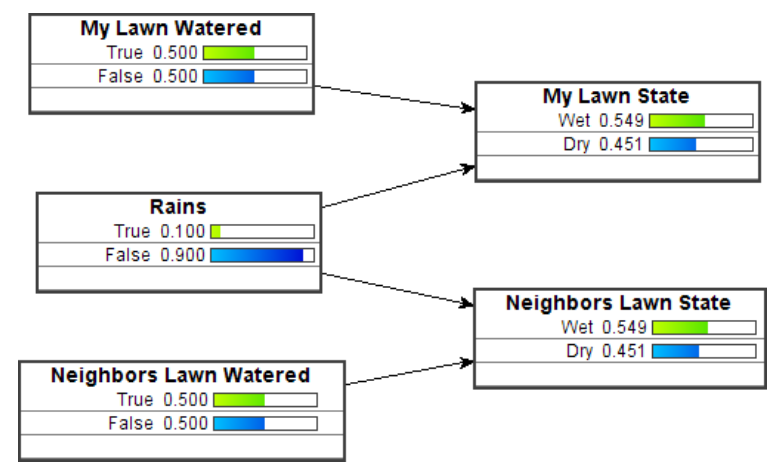

Figure 5.3. Lawn Watering or Rain?

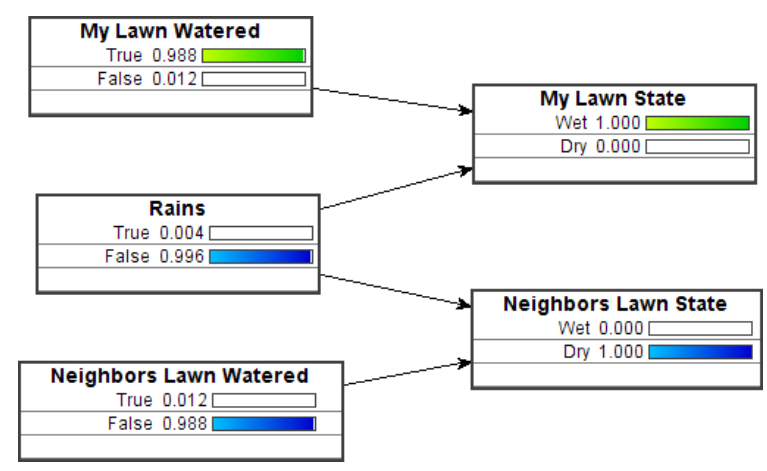

Figure 5.4. Network Given My Lawn Is Wet and My Neighbor's Lawn Is Dry 
Figure 5.5 displays a Bayes Net representation of Sani's work on the social psychology of group schism (Sani 2005). The nodes represent the critical concepts identified in the literature. In this model, each of concepts has two state values (Low/High, or Present/Absent). The numeric values are the marginal probabilities for the state values. The model propagates probability values through the network, so that if a value changes (based on evidence or opinion) in one part of the model, corresponding changes in probability values are observed in the other parts of the model. When a group splits, one of the resulting groups shows a higher propensity towards violent behavior. The tendency towards group schism therefore constitutes a useful diagnostic for the emergence of violent behavior.

Building Bayes Nets that represent reliable social and behavioral constructs requires identifying key factors from within social science theories and establishing relationships among such factors so that the Bayes Net model built reflects the insights of the social science theories used as sources. For instance, the group schism model shown in Figure 5.5 was developed by distilling key factors from Sani's theory of group schism to establish the nodes within the model and identifying relationships across the factors in Sani's theory to link the nodes in the model. For example, the voice indicator conceptualizes the extent to which a faction within a group has effective means of expressing its position. A low value for voice signals the increasing likelihood that the group may splinter. Similarly, a higher value for the intergroup differential or conflict indicator can lead to reduction in group cohesion with consequent weakening of the group identity leading to higher likelihood that schism intentions may proliferate.

By quantifying indicators of violent intent that social science literature only qualitatively describes, Bayes Nets help analysts explain and reproduce their analytic conclusions. Bayes Nets encourage analytic objectivity by explicitly reminding analysts of the larger set of relevant indicators.

\subsubsection{Validation, Verification, and Calibration}

Bayes Nets represent the joint probability distribution of the random variables shown in the nodes of the network. The extent to which the random variables in the nodes are observable corresponds with the extent to which the network may be empirically validated. In this case that the nodes are observable, calibration is accomplished by statistical parameter estimation, and validation is accomplished by a goodness-of-fit calculation. For instance, if the variables are discrete, then a Chi-square statistic would be a standard approach for a goodness-of-fit validation calculation.

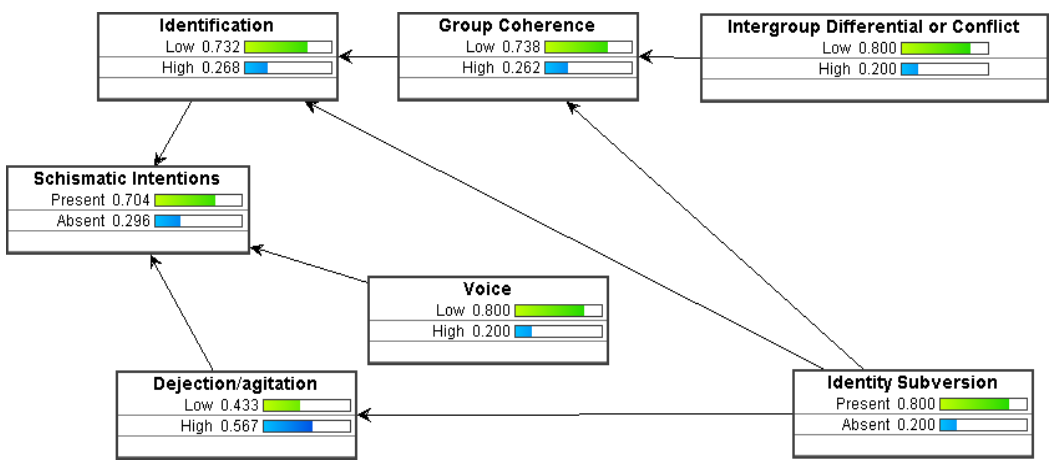

Figure 5.5. Bayes Net Representation of Model Assessing Likelihood of a Group Split

In terms of verification, validation, and calibration, despite the existence of well-known calibration and validation approaches, a key concern is that each of the Bayes Net models is based on a large number 
of parameters, $10 \mathrm{~s}$ to $100 \mathrm{~s}$ in the simple networks shown in this document. This characteristic is shared by other approaches - System Dynamics, Agent Modeling, etc. To estimate and/or empirically validate a model with that number of parameters requires independent data on the order of a multiplier of the number of parameters. Case studies on a particular group or setting can be viewed as one observation.

Databases of observations can be used to validate aspects of some of the behavior models. The Minorities at Risk database ${ }^{2}$ contains characteristics of multiple groups, and is suitable for validation calculations of some behavior models.

\subsubsection{Application to Export Control License Analysis}

Bayes Nets have the potential to model both micro- and macro-level components of the export control process. Figure 5.6 shows a Bayes Net micro-level candidate model for assessing the risk of a particular export license application. The nodes show the variables influencing the assessment. Probabilistic relationships among these variables, developed in the construction of the model, control this influence. This category of model supports incorporating case evidence, and is sufficiently flexible to readily support the inclusion of diverse evidence at multiple scales. Bayes Nets can also be developed for macrolevel assessment.

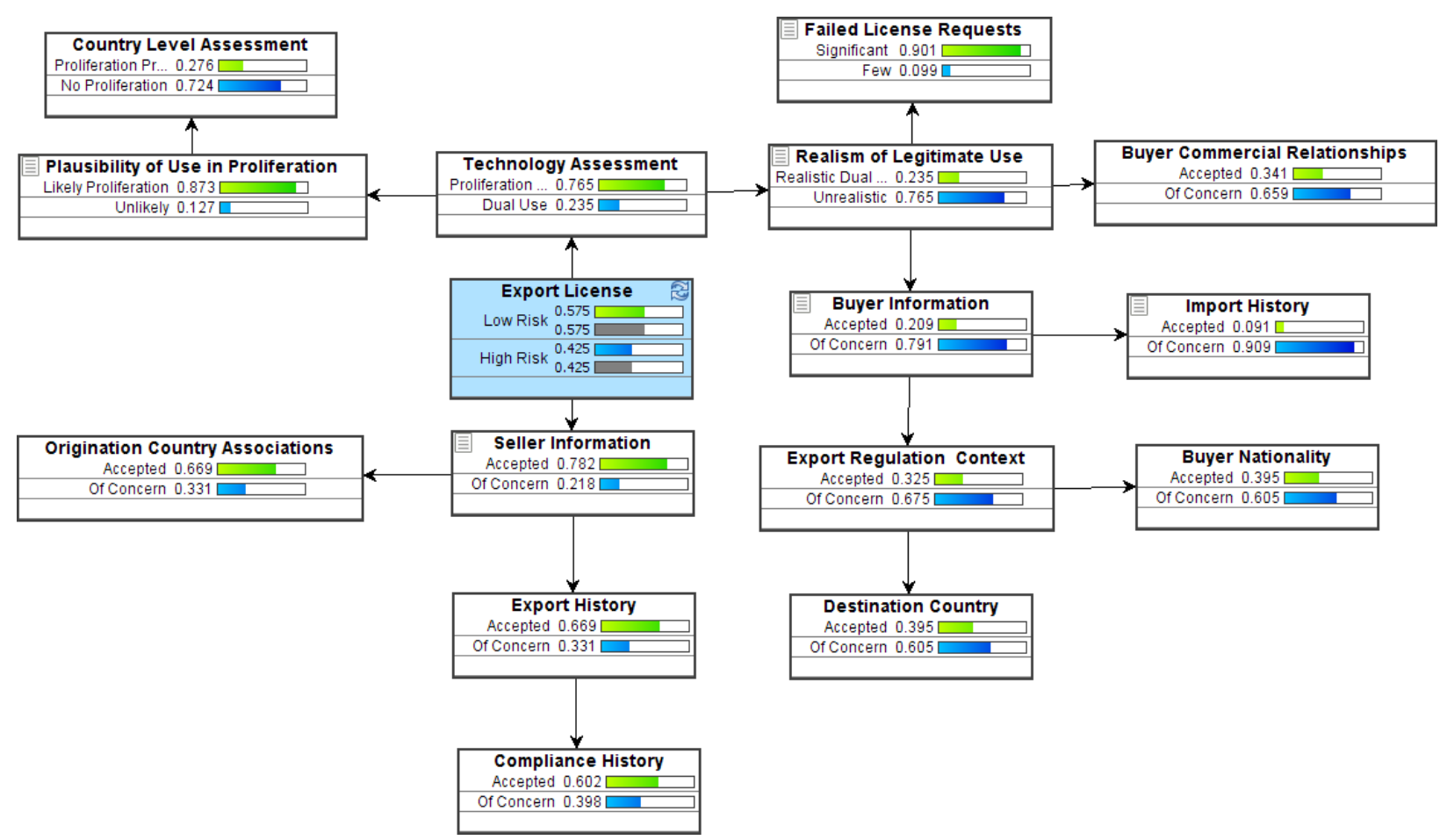

Figure 5.6. A Candidate Bayes Net Model for Supporting Analysis of License Applications

${ }^{2}$ http://www.cidem.umd.edu/mar 


\subsection{Analysis of Competing Hypotheses}

\subsubsection{Description}

Analysis of Competing Hypotheses $(\mathrm{ACH})$ is an analytic tool originally developed for intelligence analysts at the Central Intelligence Agency. It is "grounded in basic principles of cognitive psychology, decision analysis, and the scientific method." "The central principle governing ACH is that while no hypothesis can ever be conclusively proven, a hypothesis may be disproved with only one or two pieces of conclusive evidence. With limited evidence, therefore, analysts should be able to determine which hypothesis, from a comprehensive list, can be ruled out. With this in mind, ACH guides analysts through an eight-step process that pits all possible hypotheses against each other, with the focus remaining on disproving, rather than proving, the possibilities. This approach helps analysts avoid several typical pitfalls: 1) satisficing, wherein an analyst selects one probable hypothesis and then amasses evidence supporting the favored hypothesis; this approach leads people to overlook conflicting evidence, or place significantly less weight on it than they do on evidence that proves the hypothesis they have chosen; 2) anchoring, which describes the human tendency to select a preconceived endpoint, then adjust that endpoint when evidence suggests the original estimate was incorrect; this effect causes insufficient adjustments, so that the final estimate will remain too close to even an arbitrarily chosen anchor; 3 ) unexamined assumptions, which influence conclusions without ever becoming explicit; if the steps in $\mathrm{ACH}$ are performed correctly, underlying assumptions, perceptions of foreign countries, and personal biases are taken into account; and 4) missing evidence, which may easily be overlooked, that might be significant for its absence alone.

Step 1 in ACH identifies all reasonable hypotheses. This may be the most important step in the process. In Figure 5.7, four hypotheses are related to an individual license application. Step 2 focuses on identification of all significant evidence. Evidence can include assumptions, deductions, measurements, or any other sources of information. Lack of information or conflicting information should also be identified and can serve as evidence. Step 3 is to fill out the diagnostic matrix by ranking each piece of evidence as consistent or inconsistent with the hypotheses. The focus of Step 3 is to rule out hypotheses or identify missing hypotheses. Step 4 rates the credibility and relevance of each piece of evidence. In Step 5, the matrix is refined through identification of additional hypotheses or evidence. Step 6 focuses on removing hypotheses that are disproved by the evidence. Step 7 ranks the remaining hypotheses, and Step 8 sanity checks the entire process.

\subsubsection{Validation, Verification, and Calibration}

In general, ACH models are focused on helping analysts to remove hypotheses that do not fit the data. However, $\mathrm{ACH}$ models do not provide a quantitative assessment of the strength of information supporting hypotheses. The verification, validation, and calibration of such a modeling scheme is very limited. In terms of good analysis and forecasting practices, ACH's focus is on improving analytical thought processes, and working within the intelligence analysis workflow. For these reasons, ACH could serve to

\footnotetext{
${ }^{3}$ For a full explanation of ACH, see Chapter 8 of Heuer 1999, which can be accessed at https://www.cia.gov/library/center-for-the-study-of-intelligence/csi-publications/books-andmonographs/psychology-of-intelligence-analysis/index.html
} 
improve the individual analyst's workflow, and could work in concert with other models; but, ACH is not a modeling capability in the same sense that Bayes Nets, or System Dynamics, are modeling capabilities.

\begin{tabular}{|c|c|c|c|c|c|c|c|c|c|}
\hline \multirow{2}{*}{$\begin{array}{l}\text { Iter } \\
\text { thesis } \\
\text { (10) }\end{array}$} & $\begin{array}{cc}\text { Enter } & \text { Sort } \\
\text { Evidence } & \text { Evidence By: }\end{array}$ & Order Added & \multicolumn{2}{|c|}{$\begin{array}{c}\text { Type } \\
\text { of Calculation: }\end{array}$} & \multicolumn{2}{|c|}{ Weighted Inconsistency Score } & \multirow[t]{2}{*}{$\begin{array}{c}\text { Duplicate } \\
\text { Matrix }\end{array}$} & \multicolumn{2}{|l|}{$\begin{array}{l}\text { Hide/Show Hide } \\
\text { Columns Tutorial }\end{array}$} \\
\hline & & \multicolumn{2}{|c|}{$\mathrm{H}: 1$} & & $\mathrm{H}: 2$ & $\mathrm{H}: 3$ & & $\mathrm{H}: 4$ & $p$ \\
\hline & & \multicolumn{2}{|c|}{$\begin{array}{l}\text { The proposed license } \\
\text { application has a legitimate } \\
\text { dual use as identified in the } \\
\text { application. }\end{array}$} & $\begin{array}{l}\text { The pr } \\
\text { applica } \\
\text { dual us } \\
\text { in the } \\
\text { errors }\end{array}$ & $\begin{array}{l}\text { roposed license } \\
\text { ation has a legitimate } \\
\text { se but not as identified } \\
\text { application (simple } \\
\text { on the application). }\end{array}$ & \multicolumn{2}{|c|}{$\begin{array}{l}\text { The proposed license } \\
\text { application is at risk to be } \\
\text { used directly for immediate } \\
\text { proliferation use. }\end{array}$} & $\begin{array}{l}\text { The proposed license } \\
\text { application is at high risk for } \\
\text { proliferation through } \\
\text { subsequent transfers. }\end{array}$ & \\
\hline & $\begin{array}{c}\text { Weighted Inconsistency } \\
\text { Score } \Rightarrow\end{array}$ & \multicolumn{2}{|c|}{-0.0} & & .0 .0 & \multicolumn{2}{|c|}{.7 .0} & -5.0 & \\
\hline \multicolumn{10}{|c|}{ Enter Evidence } \\
\hline & $\begin{array}{l}\text { Country has significant } \\
\text { export control procedures }\end{array}$ & \multicolumn{2}{|c|}{$\mathrm{C}$} & & C & \multicolumn{2}{|r|}{11} & II & \\
\hline & $\begin{array}{l}\text { Country has no proliferation } \\
\text { program }\end{array}$ & \multicolumn{2}{|c|}{$\mathrm{C}$} & & C & \multicolumn{2}{|r|}{ II } & $\mathrm{C}$ & \\
\hline & $\begin{array}{l}\text { Buyer is legitimate (regular } \\
\text { buyer, experience in dual } \\
\text { use of item) }\end{array}$ & \multicolumn{2}{|c|}{$\mathrm{CC}$} & & $\mathrm{C}$ & \multicolumn{2}{|r|}{ II } & 1 & \\
\hline & $\begin{array}{l}\text { Seller is legitimate (regular } \\
\text { supplier, knowledgable of } \\
\text { regulations) }\end{array}$ & \multicolumn{2}{|c|}{ C } & & $\mathrm{c}$ & \multicolumn{2}{|r|}{ N } & 1 & \\
\hline & $\begin{array}{l}\text { Dual Use rational fits } \\
\text { location }\end{array}$ & \multicolumn{2}{|c|}{$\mathrm{C}$} & & $\mathrm{N}$ & \multicolumn{2}{|r|}{ I } & $\mathrm{N}$ & \\
\hline & End use location exists & \multicolumn{2}{|c|}{$\mathrm{CC}$} & & $\mathrm{N}$ & \multicolumn{2}{|r|}{$\mathrm{N}$} & 1 & \\
\hline
\end{tabular}

Figure 5.7. Example ACH for Export Control Example

\subsubsection{Application to Export Control License Analysis}

In terms of the micro-level export control problem, the ACH methodology can facilitate identification and organization of evidence, as well as identify and evaluate proliferation-assessment hypotheses. ACH can also be developed for macro-level assessment, in that a country's goals for nuclear energy can be developed into hypotheses. The hypotheses for country-level assessment include 1) the country has no interest in nuclear technology, 2) the country requires nuclear energy to support its current energy needs, 3 ) the country is developing nuclear energy to support future energy needs, 4) the country is developing nuclear technology to elicit international support in exchange for ending proliferation, 5) the country is developing nuclear weapons to equal the technology of their enemy, or 6) the country is developing nuclear weapons to go to war.

\subsection{System Dynamics Models}

System Dynamics (SD) models are useful for understanding the impacts of policy and individual decisions on the overall behavior of a system. They can complement other modeling approaches with the unique insights they provide. In a 35-year retrospective on SD modeling, Jay Forrester claims that policy seldom has the intended impact on the behavior of a system (Forrester 1991). System Dynamics modeling is a method of understanding the complex behavior of systems, such as export control, that can guide policy and test whether specific interventions are having the desired consequence. 


\subsubsection{Description}

System Dynamics models are built in order to understand complex systems and the impact of policy on the behavior of the system. They represent cause and effect relationships and how the decisions of multiple entities interact to produce an overall behavior that is often non-intuitive and would be difficult if not impossible to predict in the absence of the model. System Dynamics was originally developed to understand complex systems in which feedback loops create a non-linearity. It grew from work in electrical engineering, but has been applied to studying complex systems in a wide variety of applications. Initial applications focused on understanding business organizations as a system. Subsequent applications include such diverse areas as the interactions between species in a natural ecology (Ford 1999), understanding stagnation and growth in cities (Forrester 1969), and understanding population and resource dynamics on a global level (Meadows et al. 2004). It is applicable to any system in which there are complex interactions among variables over time and characterized by individual variables feeding back on themselves. The models are typically developed from expert knowledge. Individual feedback loops within the model are usually intuitive, whereas when combined their interactions result in complex system whose behavior is difficult to predict in advance of running a simulation using the model.

\subsubsection{Causal Diagrams}

The key to understanding and building SD models is understanding cause and effect relationships. ${ }^{4,5,6}$ The building blocks of SD models are causal links between two variables. Of particular interest in SD models is a series of variables in a chain of cause-and-effect relationships that loops back onto itself to create feedback. Figure 5.8 is an example of a causal loop illustrating feedback (Roberts et al. 1983). The room temperature affects thermostat activity, which in turn controls the furnace, which affects the radiator activity, which changes the room temperature.

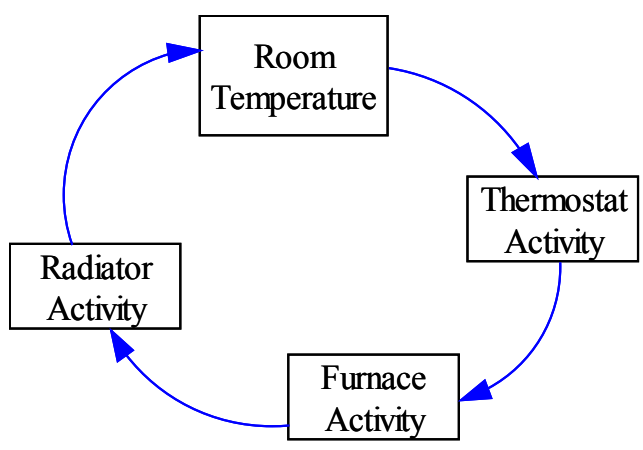

Figure 5.8. A Feedback Loop

\footnotetext{
4 "Causal thinking is the key to organizing ideas in a system dynamics study" (Roberts et al. 1983).

5 "The feedback structure of an organization can dominate decision making far beyond the realization of people in that system. By a feedback structure, I mean a setting where existing conditions lead to decisions that cause changes in the surrounding conditions, that later influence later decisions" (Forrester 1991).

${ }^{6}$ The concepts of cause and influence are central to peoples' mental models (Senge 1990).
} 
Causal loops are of interest in SD because they form a closed system that can be understood independent of outside influences. Causal loops can be compensating (stable) or reinforcing (unstable). A compensating loop is shown in Figure 5.9 (Roberts et al. 1983).

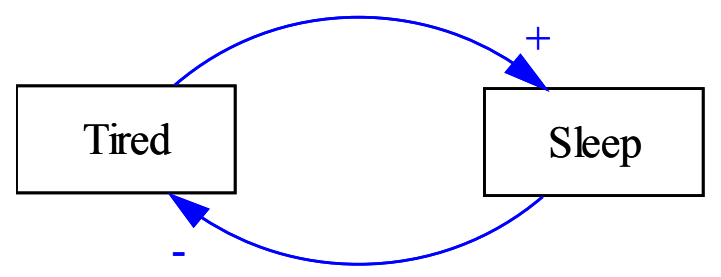

Figure 5.9. Compensation Loop Between Sleep and Tiredness

An increase in tiredness causes an increase in sleep as denoted by the plus sign in the diagrams. The more one sleeps the less tired one becomes as denoted by the minus sign in the diagram. The less tired one is, the less one sleeps, which is indicated by the positive correlation. Thus, this causal loop is stable. In general, loops with an odd number of negative correlations tend to be stable.

An example of a reinforcing causal loop is shown in Figure 5.10. The amount of interest paid in a year depends on the bank balance. The greater the bank balance the greater the interest paid for a given interest rate. Also, the smaller the bank balance the less the amount of interest paid. This direct relationship between the bank balance and the amount of interest is indicated by a plus sign at the head of the arrow in Figure 5.10. Also, the greater the amount of interest paid per year, the greater the bank balance.

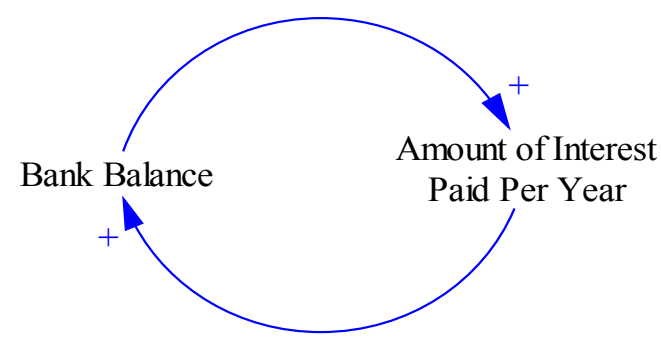

Figure 5.10. System Dynamics Representation of Bank Balance and Interest Paid

\subsubsection{Verification, Validation, and Calibration}

The validation of SD models is well documented (see Barlas 1996). The Barlas reference presents multiple aspects of validation for SD. The author separates the task of validating the structure of the model from validating the behavior of the mode, and finally the empirical goodness-of-fit of the model with the data.

\subsubsection{Application to Export Control License Analysis}

How useful would this model be for export control? For predictions of export control violations, a Bayes Net built around indicators as evidence is the most direct modeling approach. However, an SD model could be useful in understanding the impact of policy changes directed at controlling violations. 
To the extent that the system of export control involves a number of individuals, some of whom are working to prevent violations while others are trying to circumvent the rules, and the overall system behavior is complex, then an SD model could be useful in deciding how best to intervene. This is a slightly different problem than detection, which may best be carried out by a Bayes Net. There have been some attempts to combine Bayes Nets with SD models, and this approach may warrant further exploration.

The loop shown in Figure 5.11 models the arms race between the United States and the Soviets during the Cold War (Senge 1990). Americans viewed the Union of Soviet Socialist Republics' arms as a threat, which resulted in more U.S. arms, which was in turn a threat to the Soviets, who increased the number of their arms, and it continued to spiral out of control. The cost of increasing arms was eventually the undoing of the Soviet economy, which put an end to the arms race and the Cold War.

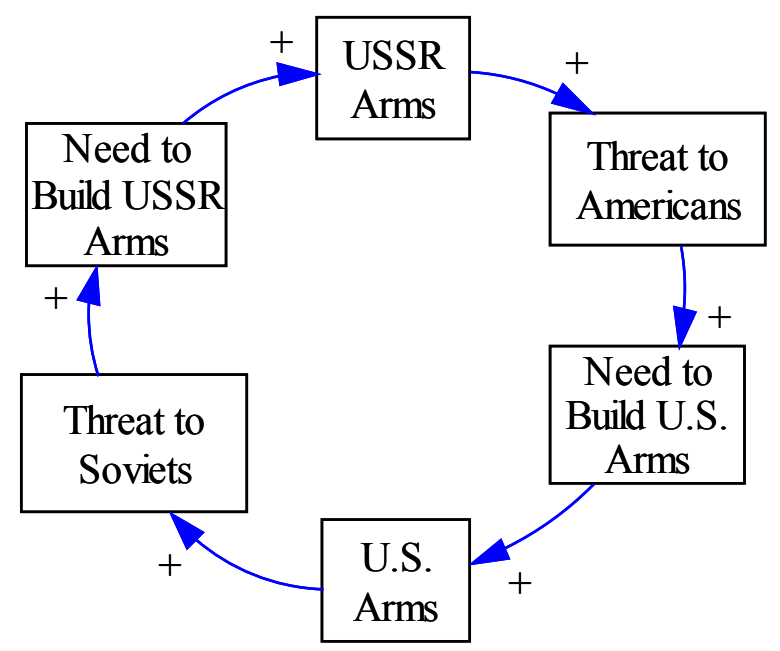

Figure 5.11. Example of Unstable Causal Loop

Tertrais (2007) has described the history of nuclear proliferation with respect to Pakistan. As he describes it, the history has a number causal relationships that lend themselves to SD modeling. Some of these relationships are shown in Figure 5.12. Tertrais described how after India carried out nuclear tests, Western nations became increasingly concerned about proliferations, which led to Western nations increasing restrictions on exports to Pakistan. This had a number of unintended consequences. First, Pakistan turned to the Chinese to obtain nuclear technology, resulting in an increase in their nuclear capability. Pakistan also became more creative in its importing of nuclear technology, such as having a nuclear component buried in a long list of useless material or obtaining a single example of a critical component and then manufacturing it themselves. Pakistan also began a secret import program consisting of multiple organizations and government bodies. The net result was increased Pakistani nuclear capability, rather than less as intended by an increase in Western restrictions. 


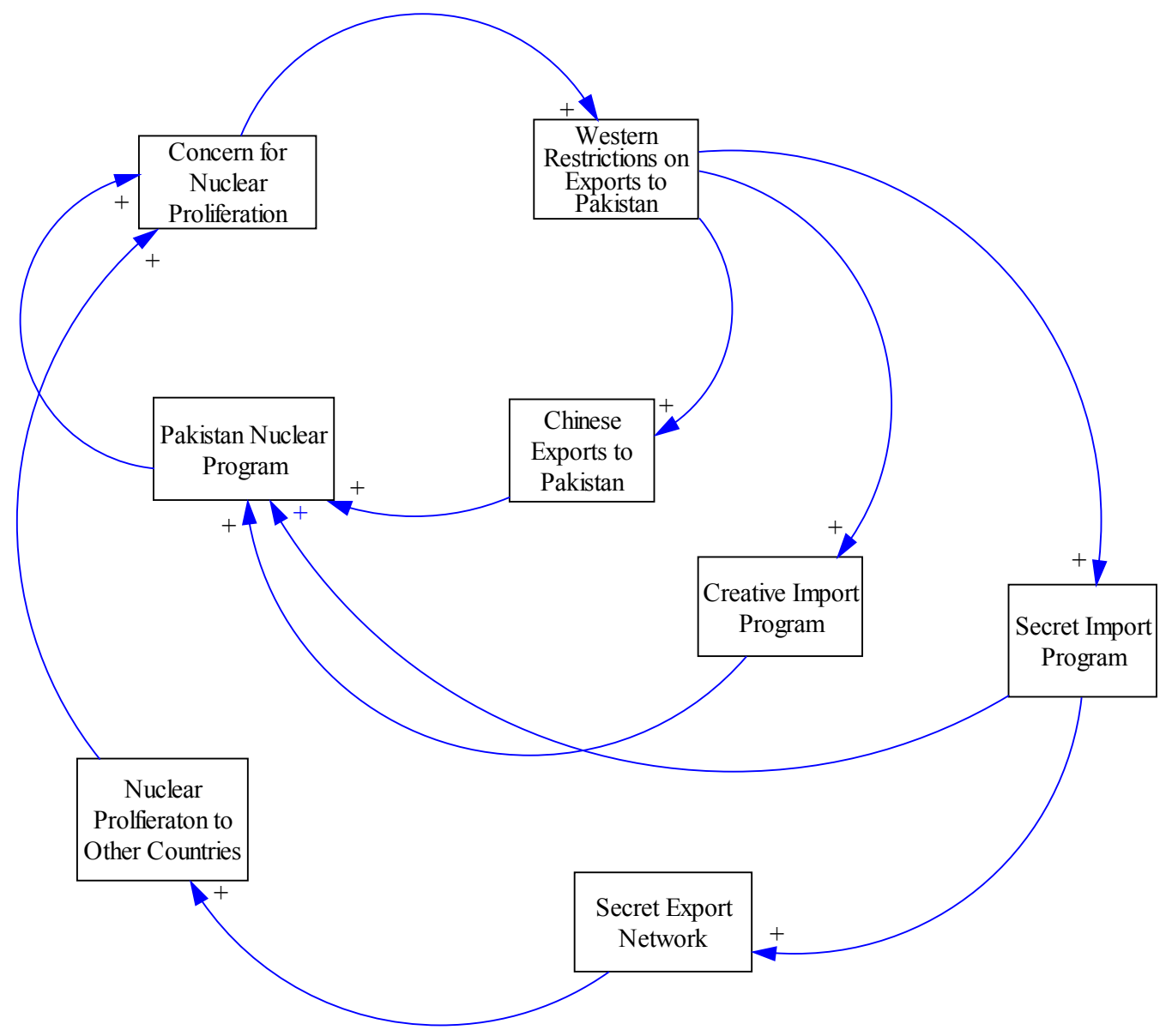

Figure 5.12. Tertrais's System Dynamics Model of Pakistan

There was another unintended consequence of Pakistan's secret import program. The Pakistanis were able to use the network they created for nuclear technology imports to turn around and export technology. Pakistan's secret export program provided nuclear technology to North Korea, Iran, Iraq, and Libya.

\subsection{Input/Output Economic Models}

\subsubsection{Introduction}

The neoclassical economic input/output model describes a country or region's economy in terms of the requirements of industries to produce the current level of economic output. By adding a trade sector to the make and use matrices, the input/output model can become a multi-regional description of economic output and trade flows (Löfgren and Robinson 1999). The use matrix describes the inputs required to make a dollar of output in a specific industry. In this application, the use matrix for a country would describe the requirements of the dual-use items in that country's economy. The addition of trade flows can improve the quality of information provided by the model by forecasting where dual-use items would travel if exports to the particular country were greater than its needs as determined by the use matrix. 


\subsubsection{Description}

The input/output model used as a tool to detect improper exports of dual-use commodities would be an extension of the classical Leontief model (Coon et al. 1985; Löfgren and Robinson 1999; NWT Bureau of Statistics 2006; ten Raa 2005) used to calculate the economic impacts of exogenous events on an economy. The typical input/output model describes economies using square invertible matrices where the columns are industries and rows are commodity requirements of each of the industries.

Figure 5.13 shows a representation of a transactions table for an input/output model for a hypothetical four-sector economy with imports and final demand where exports are part of final demand. For example, $X_{\mathrm{aa}}$ is the amount of agricultural commodities used in the agricultural industry. $X_{\mathrm{ma}}$ represents the amount of agricultural commodities used in the manufacturing industry. Summing the amount of commodities plus Final Demand is equal to total output. The $\mathrm{X}$ coefficients must be a square matrix for matrix inversion. Mathematically, the economy can be expressed as

$$
\text { eq. 1) } \quad Y_{i}=\sum_{j=1}^{n} X_{i j}+C_{i}
$$

where $Y_{i}=$ total output for sector $\mathrm{i}$

$\mathrm{X}_{\mathrm{ij}}=$ industry $\mathrm{i}$ 's inputs from commodity $\mathrm{j}$

$\mathrm{C}_{\mathrm{i}}=$ final demand of commodity $\mathrm{i}$ (which can include exports)

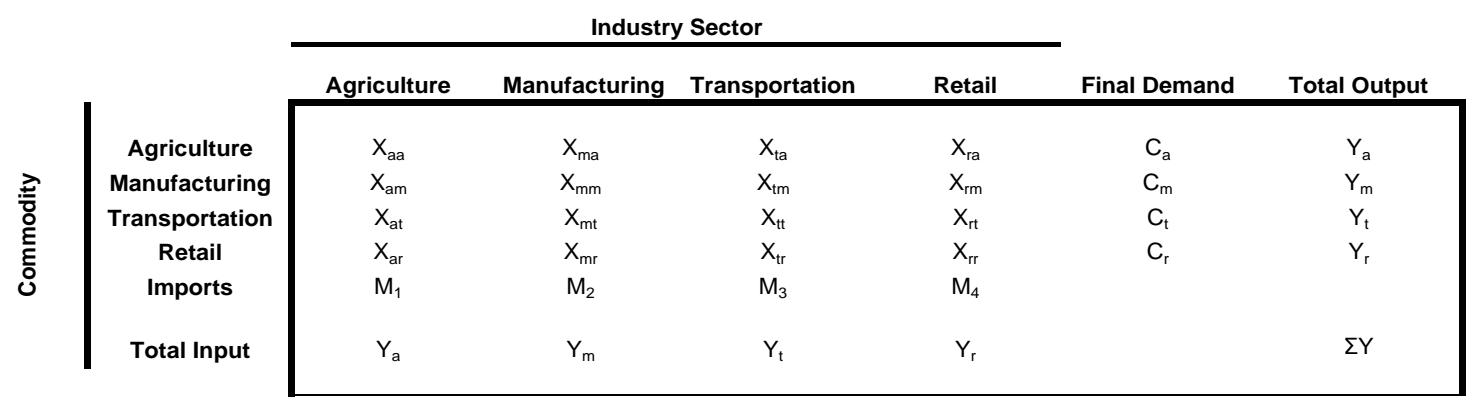

Figure 5.13. Representation of Transactions Table for Economy

Input/output coefficients can be derived from the above table by deriving the amount of total input from commodity i used in industry $\mathrm{j}$ as shown in Equation (2).

$$
\text { eq. 2) } a_{i j}=\frac{X_{i j}}{Y_{j}}
$$

The resulting values can be seen in Figure 5.14. 


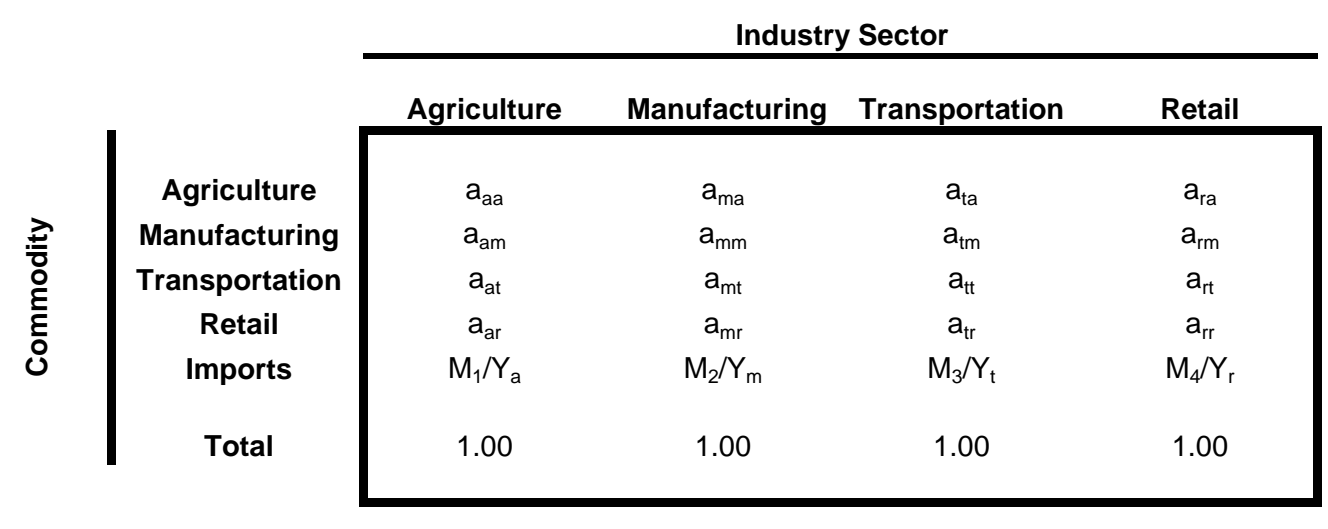

Figure 5.14. Technical Coefficients Table of the Representative Economy

The final step is inverting the matrix to obtain the multipliers for each industry. Only the $\mathrm{a}_{\mathrm{ij}}$ 's are used in this step. In matrix notation:

where I is the identity matrix.

$$
\begin{aligned}
& Y=A Y+C \\
& Y=[I-A]^{-1} C
\end{aligned}
$$

The sum of the multipliers by industry $i$ is the gross receipts multiplier for an additional dollar of final demand in commodity $i$.

Input/output models using national accounts data are too highly aggregated to be useful for evaluating a world economy for applicable legal uses of dual-use commodities. The high degree of aggregation makes directly identifying the requirements for a dual-use item nearly impossible. However, there is significant literature on disaggregating the input/output model so that useful conclusions can be made at a more detailed level of the economy.

The national input/output model however is a useful starting point. The United Nations (UN) provides a uniform approach to national accounting (UN 2008), which is the basis of the macroeconomic input/output table. Thus, the UN data provide a common methodology for determining the detailed data behind the aggregated accounts. The United Nations has 169 participating countries for detailed data on the main aggregates of the national accounts. The biggest issue associated with input/output models that describe the world economy is that they are data intensive.

As mentioned previously, the Leontief input/output model requires a square matrix of the industry/commodity makeup of an economy. Without the square nature of the table, the matrix could not be inverted to determine the impact of exogenous events upon the economy. The extensions to the common Leontief input/output model will include developing commodity requirement matrices that incorporate the more detailed uses by industry associated with the dual-use commodities. The remaining requirements of commodities by industries would remain highly aggregated. In order for the inversion process to be completed the disaggregated commodities would be aggregated until the number of commodities equals the number of industries in the input/output table. Only dual-use commodities would be called out in detail. 
Other extensions to the input/output model could be used to improve its predictability in an interregional trade model. Those extensions would include the prices and pricing, along with international trade framework. With these extensions, the input/output model can allow surplus trade to move to its highest value within the framework of the model, which could allow analysts to trace exports from stated to probable destinations (Hoffman and Kent 2005; Liew 2000; Marriott 2007).

\subsubsection{Macro/Micro Environment Applications}

The input/output model could possibly play in both the macro environment, as well as the micro environment. Whether the input/output model can play in the micro environment depends on the level of disaggregation in the requirements matrix. If the requirements matrix can be disaggregated to a level commensurate with evaluating whether an economy needs the amount of dual-use items listed, then the input/output model can be used to evaluate directly the probability that a license should be granted. In the micro environment, proposed transactions would be fed into the model as a harmonized tariff schedule code and entered into the model as a shock to the economy.

For example, in the TSG example described previously, the number of TSGs required by the economy of the importing country would be determined based on the TSGs share of the requirements of the health industry of that economy. Based on the health industry's share, the response would be zero if no demand for TSGs existed; appropriate (which would be a part of the research) if the number of TSGs was within the requirement; or exaggerated if the quantity of TSGs was greater than the requirement. A part of the calibration would be to determine when the response was appropriate or exaggerated. A zero response would be an immediate signal that the export license should be investigated.

In the macro environment, input/output models can evaluate a nation's capability to use dual-use technology in its economy. If a nation's capability were modeled in a trade environment, the model could be used to see which country is the most likely final location for a particular dual-use commodity.

\subsubsection{Verification, Validation, and Calibration}

Model verification, validation, and calibration is a three-step process. In the first step, the model is reviewed to ensure that the equations and parameters have been correctly entered. In the second step, the model is tested with both legitimate trades and export control violations to review whether the correct response from the model was triggered. Lastly, the model is calibrated to fit the data on a country-bycountry basis.

In the verification step, the input/output model is examined to ensure that the equations and data have been correctly input into the model. Further verification can be undertaken by providing shocks to the economy and determining whether the response to the shock is as expected. This diagnostic testing is done prior to validation and calibration of the model.

The validation of the model is usually iterative because interdependent economies are going to lead to interdependent responses. Changing values in one part of the model are likely to affect other parts of the model in unanticipated ways. One of the significant issues involved in input/output modeling is how to deal with missing information from surveys. Thornton and Sorli (1982) discussed problems associated 
with validating the input/output model after forecasted data had been substituted for missing information. According to Mickle (1998) the most important point is predicting past outcomes with the model.

Once the model has been tested and the resulting changes in output are deemed appropriate, calibration of the model can be undertaken. In the calibration step, two independent steps are undertaken. The first is taking known cases and implementing them into the model to ensure that the model is tracking increases in output and trade flows based on the changes implemented into the model. In the second step, the model is calibrated using known export control license cases.

\subsubsection{Support for Export License Assessment and Associated Analysis}

Input/output models can meet a number of the desirable properties needed for export license assessment. Based on the dual-use technology, the model can evaluate where the product would likely go if it wasn't used in the stated destination country. The model processes are fairly transparent. At this point no intricate calculations are required to implement a basic input/output model with trade assumed. The input/output model will tell the analyst whether it is likely that a country could use the amount of dual-use items listed. Multiple runs of the input/output model can be used to change parameters and determine how much those changes in parameters would change the results.

Input/output models can directly use the quantities of dual-use items using concordances of the harmonized tariff schedule (HTS) to Standardized Industrialized Trade Classification (SITC) codes and the International Standardized Industrial Classifications (ISIC). The HTS is a standardized trade system that all countries use to report trade values from all countries to the United Nations. The SITC and ISIC concordances allow values from the HTS to be directed to appropriate industrial classifications of the input/output table.

Information about dual-use products and the industries that consume them can be used to develop the requirements matrices for the input/output model. The actual items and industries that use them and the amounts used in accordance with the appropriate unit of output will need to be identified. Data from external sources are likely to be required to complete the requirements matrix.

As previously mentioned, the input/output models can incorporate uncertainty by undertaking multiple outcomes and changing the basis of the input. The change in the outcome provides the uncertainty. Uncertainty can be handled in other ways such as using Monte Carlo analysis.

Input/output models are usually standardized to a particular period because that is when surveys are created that allow commodities and industries to be compared on a detailed basis. Input/output model data can easily be changed, but care must be taken to ensure that the resulting model is still valid. This analysis requires that the model be revalidated and recalibrated.

Typical input/output models are not temporal in nature, but adaptations of the input/output model have been developed, such as the computable general equilibrium (CGE) model, which incorporates time paths that move economies from one state in time to another. As one moves toward the CGE model, the level of transparency in the model declines.

Smuggling and theft cannot be directly modeled in an input/output model because smuggling occurs outside the system of national accounts. However, changes in a country's economy might be seen 
through the indirect effects of smuggling. Indirect effects are those that occur as a result of spending illicitly earned money within an economy, which in turn drives industrial production, consumption, or trade. The analyst could analyze whether an economy's change in Gross Domestic Product (GDP) is expected given its standardized accounts. Any unexpected change in GDP, given past characteristics, could indicate a change in the level of smuggling. It would not capture smuggling if it was already occurring. However, such change needs careful evaluation because there could be many reasons for changes in input parameters, including a change in the economy's structure or technology set.

Variants of the input/output model with trade could provide what-if analysis, which could allow the analyst to determine whether trade sent to certain countries would in turn end up elsewhere. This would require pricing and exchange rate information for the commodities along with information about the elasticity of demand

The input/output model would not have any characteristics that would allow its use in analyzing the political climate of involved regions. Input/output models don't usually use political nuances to determine how an economy would change. Only to the extent that the political nuances can be shown to change the economic underpinnings could those nuances be evaluated. In addition, the characteristics of the individuals and organizations involved are not attributes that any direct variant of the input/output model could provide for analysis.

As mentioned earlier, disaggregated versions of the input/output model could answer whether a nation could use the technology in a legitimate industry. This could be done simply by evaluating whether the amount requested for export is less than that used by the industry to which it is being shipped. Considerable disaggregation would be required to get down to the level of knowing whether the proposed licensee has requirements of that level.

Again, variants of the input/output model could determine where a licensed matter is likely to end up. Models would require a trade section and the value of the licensed matter would need to show up where it has the highest value. Countries with higher than ordinary market values for items used in illicit State or terrorist organization purposes could indicate where that product might end up. The model cannot tell the analyst whether the licensed material is to be used for WMD directly; but based upon subsequent transfers of the technology, it could be a piece of the information that leads the analyst to reach such a conclusion.

\subsection{Distance Model}

\subsubsection{Introduction}

One class of economic models that shows some promise for the evaluation of technology transfer risk is based on the concept of "economic distance." The concept of economic distance or more generally "transaction impedance" captures the net effect of all factors that make transactions less likely in the chosen setting. These models are structured around explicit or latent networks that link actors in technology transfer settings. These settings can represent routine commercial relationships or potential relations based on characteristics of the actors. (For example, the economic distance between two countries might depend on shared language, shared banking models, functioning currency markets, etc). 
Several years ago, PNNL developed some models for use in assessing likely indirect trade routes for sensitive technology diffusion through trade. These models may be applied to evaluation of specific cases for NA-24, and could be adapted to other data sets as well. In addition, NA-243's missions suggest other economic models that could be useful as well. All of these model application and development tasks are described in Wood et al (2006). This section establishes the context, assumptions, and implied applicability of these models.

\subsubsection{Network Models}

Network models have been applied to trade and technology diffusion in many contexts. The first application to a proliferation problem was reported in an article in the Nonproliferation Review (Morstein et al. 2000) that dealt with the pathways through which material and equipment was assembled in Iraq during the 1980s. The article suggested that a distinct class of countries (often unwittingly) played the role of intermediaries in the transfer of technology. Morstein's network is shown in Figure 5.15.

In 2002 and 2003, PNNL generalized Morstein et al.'s concept to sensitive trade data for the global economy using an "economic distance" measure derived from standard gravity models of trade. The fact that this measure is frequently non-metric can be exploited to define "short" or low impedance paths from holders of technology to those who might seek it for weapons. This class of models is still being evaluated, but appears to very clearly identify compact and distinct sets of countries that are strongly "intermediate" between holders of sensitive technology and proliferants.

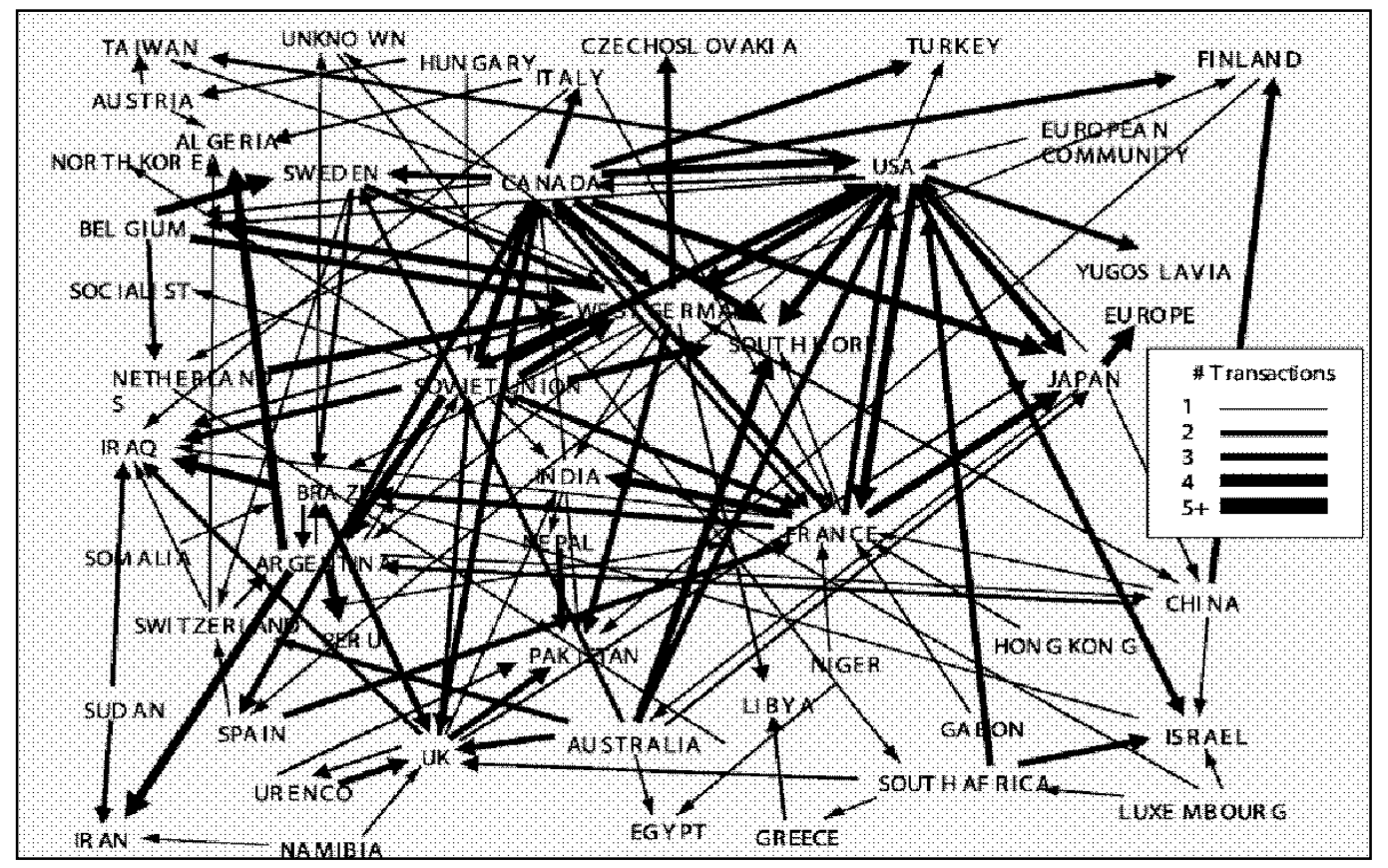

Figure 5.15. Network for Uranium Transfer (Morstein et al. 2000)

This class of models may be described as "self-structuring" in the sense that transactions and related characteristics among a set of entities implicitly define the density of network connections between entities, and the question of "probable" diffusion in such networks is then calculated directly. The logic used for defining these networks is shown in Figure 5.16. 


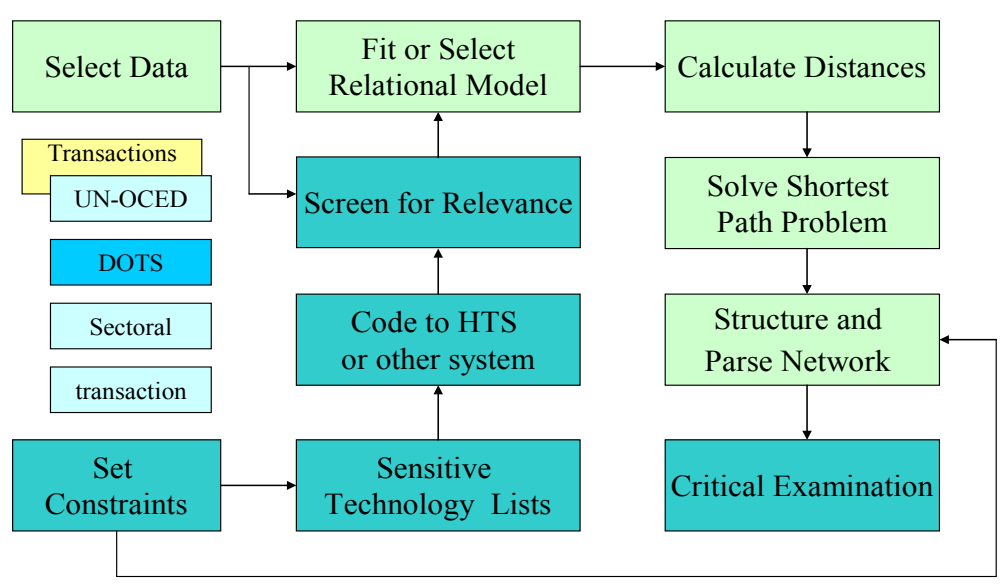

Figure 5.16. Scheme for Network Definition

The properties of such networks defined on global sensitive technology trade data proved to be quite interesting. When these networks are solved for the "shortest" or minimum impedance paths between any two entities (countries in this case), the results showed typical measures of economic distance to be nonmetric; i.e., the least impedance path for technology transfer might well be an indirect path. This result was surprisingly frequent at the country level of aggregation, as shown in Figure 5.17.

Figure 5.17 represents results for 672 country-pairs, representing all combinations of the (then) 32 countries in the Nuclear Suppliers Group (NSG) and the (then) 21 countries on the DOE sensitive country list (SCL). This specification of the network thus roughly represented the transfer of technology from "nuclear technology haves" to those we might prefer not have it.
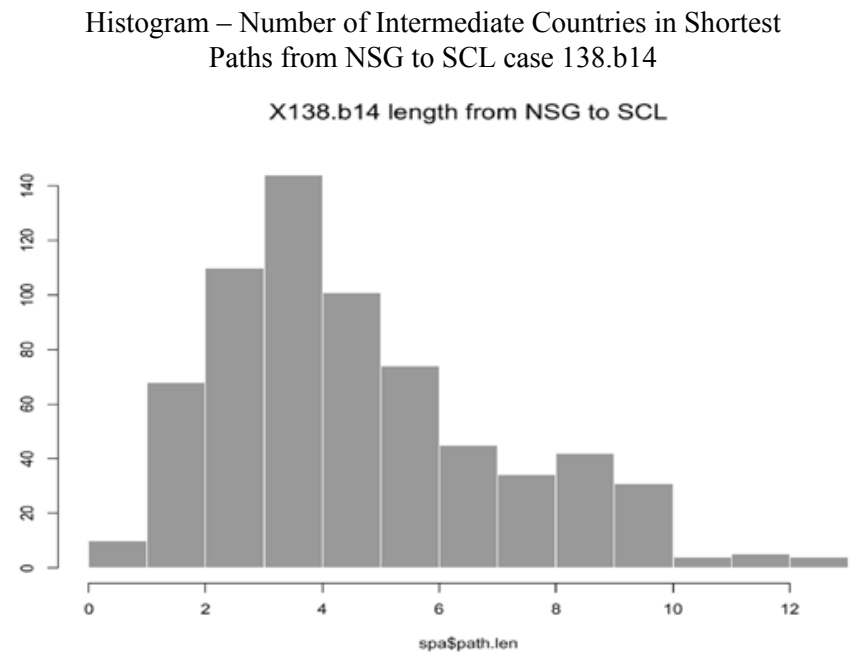

Figure 5.17. Numbers of Steps in Shortest Paths from NSG to SCL

The assumption in this model is that the same factors that motivate and condition legitimate technology trade will be operative for transfer of sensitive technology in general. While this assumption is arguable, it is in our opinion the simple starting point for evaluation of sensitive technology transfer. The results are striking in that very few low impedance paths are direct (i.e., one-step), and the most frequent solution in this data set is a four-step path. 
The interpretation of these results among those familiar with the export control context is that the set of strongly intermediate countries is a list of probable "transit states" or trans-shipment points. If the economic distance measure used is in fact dominated by physical distance considerations, ${ }^{7}$ and if convenience rather than subterfuge is the motivating factor, then this is a reasonable interpretation. Even if subterfuge is important, many of the more circuitous paths identified in these models are still probably worth some evaluation. So, this is a reasonable (although very narrow) interpretation, but not by any means the only reasonable interpretation.

One assumption that is implicit but very important in the current network models concerns the cost of additional country "stops" in a path. Because the models are calculating unconstrained minimum distance or minimum impedance paths, this cost is effectively zero. This is clearly unrealistic, because even if cost is no object in routing a shipment, time and incremental chance of discovery at each stop clearly are. This assumption could be easily relaxed in the network model calculations, wherein a series of constrained optimizations (with $\mathrm{n}<=1,2, \ldots, \mathrm{k}$ ) are being substituted for a single unconstrained case. This will yield (in the limit) the unconstrained minimum impedance paths and a set of Pareto efficient paths - paths for which decreased impedance can be obtained only at the cost of additional stops.

It is important to realize that nothing in the network model assumes an illicit transaction. Abstracting the interpretation of the model in this way suggests the question of how trade serves to gradually diffuse technology through economies over the course of history. In this context, the accumulation of stocks of technology (in tangible or intangible form) over time represents a risk of retransfer through a variety of means. In this interpretation, legitimate trade and normal information exchange are the dominant forces in the gradual transfer of technology. This could occur by several mechanisms and is subject to analysis using a variety of models at the mechanistic level. A survey article (Blackman 1997) identifies four general classes of models for technology diffusion: epidemic, rank, order, and stock. In general, these models have been used to examine the diffusion of environmental technologies in which there is an interest in rapid diffusion, but they should be applicable regardless of the technology involved.

It is also important to realize that nothing in the structure of the network model assumes the transfer of tangible assets. Although most of the international trade used as data in constructing the model represents trade in tangible items, two generalizations are both possible and relevant. The first is a model in which trade transactions are explicitly replaced by information transactions. We have proposed a model of this sort using World Wide Web (WWW) traffic statistics. The feasibility and utility of such a model for the export control problem needs to be established, and will depend on the specificity with which WWW domains can be specified. Another generalization of the existing model involves consideration of an "intermodal" transfer. An example would involve a scenario in which physical capital is first transferred to country 1 , followed by familiarization with the technology among the technical labor force, and then the trained laborers relocate to country 2, etc. Such a general model would need measures of technology stock, both as physical capital and information embodied in various forms.

${ }^{7}$ In fact, these measures are typically weakly correlated with physical distances. Appendix A of Wood et al. (2006) includes a set of correlations and scatter plots between various distance measures we have calculated and a set of standard physical distances provided by Boisso and Ferrantino (1997). The strongest correlation ( $\mathrm{r}-\sim .5)$ is between our distance measure derived from total trade and standard gravity model parameters. Measures of distance derived from various definitions of sensitive technology trade are less well correlated with physical distance. 


\subsubsection{Measures of Technology Stock or Capability}

The "activity" measure most typically used in gravity models of trade (and thus inherited in our distance formulation) is GDP. This is probably the most powerful single variable in predicting total trade (or for establishing distances that are predictive of total trade), but may not be the best measure for sensitive trade.

If sensitive trade is specialized (in the sense that its incidence in the input side of input/output tables is restricted to an arbitrarily small class of outputs), the activities producing this set of outputs furnish the best activity measure for the demand side of a sensitive trade gravity equation. We call this set of sectors the "output image" for a given set of technology. We could take total output from this set of sectors as a country-level measure of demand. Analogously, the output from the set of sectors producing a given set of sensitive technology ${ }^{8}$ is a measure of supply side "economic mass" suitable for a sensitive trade gravity equation. Using these activity measures in lieu of GDP should theoretically result in a better specification, and thus a more meaningful set of distances and associated diffusion paths.

Beyond using scalar measures of output as activity measures, there is also the possibility of using the input/output structure itself as indicative of the technological structure or status of a country. This approach is taken by Fukuchi and Satoh (1999) in a test of convergence theory, using technical coefficients for 21 sectors from Brazil and Indonesia to establish a "technological distance." In this context, the distance measure is the time that one economy lags another insofar as they share technological development paths. This application seemed remarkably successful, in the sense that the number of years of lag in several sectors was in good agreement using two different indices, and in many cases it was identical. A similar construction, properly framed in terms of sensitive technology sectors rather than broad industrial sectors, and calibrated to various nuclear weapons states, might make a very interesting gauge of the time to weapons competence based on industrial structure. The challenge for this model would be data availability.

A final generalization that might be considered is introducing measures of scientific (as opposed to strictly technological) status and activity in some way. In a broad sense, if technologies produce weapons, science produces technologies. Some work has been done with measuring scientific status using patents. Several other data sources suggest themselves. University degrees are a relevant measure. Fields of specialization in job openings in journals or on the web could be exploited. This approach would require adapting or developing a taxonomy of science (at least for physics and parts of other fields) and correlating this taxonomy with specific weapons technologies. This could be a big job.

\subsection{Agent-Based Simulation Modeling}

Computational agents are smart, evolving entities capable of flexible, autonomous action whose interactions over time establish a simulated economy. Useful inferences can be gained about the real nuclear technology economy and in particular export licensing through analysis of agent-based computational economics (ACE) methodologies. Inferences about proliferation risk, the characteristics of a nefarious buyer, or the efficacy of existing dual-use technology transfer licensing can be garnered

8 This is the set of HTS (or ISIC) codes that produce sensitive technology; i.e., the codes into which the various control lists were projected based on the descriptions of restricted items in the lists. 
through 1) the assembly and then 2) in the observation of an ensemble (i.e., an empirical distribution) of results from different ACE methodologies. In particular, inferences are drawn by 1) ferreting out details and data for assembly and 2) varying agent types, initial states, interaction rules, and environmental settings; simulating each variation; accumulating qualified simulations; and then probing the resulting economies' distributions.

\subsubsection{Description}

An ACE is a simulated economy raised by autonomous decision-making software entities, or agents. Each agent assesses its situation, makes decisions, and then executes a behavior appropriate for its governing methods and data. Repetitive, cooperative/competitive interactions are a signature feature; ACE modeling relies on potent computing rather than on, often intractable, mathematical methods to investigate complex systems. The benefit of agent-based modeling is the revelation of emergent micro- to macro-economic phenomena not observable by other means.

Agent-based modeling is a natural choice for describing a system of "behavioral" entities when individual behavior is autonomous, diverse, dynamic, and heterogeneous; entities' behaviors cannot be clearly defined in aggregate; stochasticity applies to an entity's behavior; individual activities, not processes, offer a more natural description; and expert judgment is important in model verification and validation (Bonabeau 2002). An agent is a self-contained, identifiable bundle of public, private, or protected methods and data; i.e., methods and data subsets with public, private, or protected access. As empowered by its methods and data, an agent can remember, learn, and adapt; recognize and respond to other agents; and may seek goals (Macal and North 2006). The general steps for assembling and exercising an agent-based model require defining the inferential objectives; identifying the relevant agent types; specifying each agent's public, private, and protected methods and data, including methods to update methods and data; simulating and then assembling realizations into an ACE distribution; and finally drawing and weighing inferences from both the modeling process and the ACE distribution.

\subsubsection{Verification, Validation, and Calibration}

Assembling a qualified ACE distribution relies upon comparison of a simulated economy to its design specifications (verification) and to the real target economy (validation). With regard to verification, the question is "do the inference-relevant aspects of the simulated economy, say export licensing, exhibit the appropriate social system of geographically distributed entities interacting through markets and other structures to produce and exchange goods, services, and information?" With regard to validation, "do the inference-relevant aspects of a simulated economy match those aspects of the real target economy?" An ACE methodology-driven economy evolves through simulation of relatively simple agent-level interactions into a complex system that can approach the target economy in undetermined complexity. Therefore, there is no simple answer to ACE methodology verification and validation. Simulated and real economies differ, however, in one key and very useful aspect: unlike a real economy, the complete history of an ACE simulation can be available for analysis - the history of every agent, transaction, and economic state (although, in practice an ACE distribution would be recorded in sufficient statistics).

Although rich in simulated and often real data, ACE methodology verification, validation, and interpretation historically have relied almost exclusively on expert judgment due to the lack of quantitative methods. Increasingly, objective quantitative methods are being used to support, balance, or 
supplant this expert judgment (Axelrod 2003; Axtell et al. 1996; Judd 2006; Wilenski and Rand 2007; Fagiola and Windrum 2007; Marks 2008). One strategy to verify, validate, and then interpret an agentbased economic model uses an empirical likelihood function to summarize and directly link an ACE distribution to the target economy. A likelihood function links a model and measurements [m-n]; here, a likelihood function links agent methods and data to simulated and real micro-, meso- and macro-scale economic measurements. An ACE likelihood function, however, is mathematically intractable. Consequently, an empirical ACE likelihood is calculated using scalable density estimation (Solka et al. 1995, 1998).

The likelihood may be parsed in order to compare the fit of components of the realized ACE distribution to an inferential objective and initial specifications (verify), and to compare the fit to the relevant aspects of the real target economy (validate). The likelihood provides guidance about the types of measurements that are informative, or not informative, with respect to a collection of competing models. In addition, there is a rich history and well-developed theory for using likelihood methods to develop and interpret models in the light of measurements.

\subsubsection{Application to Export Control License Analysis}

Export licensing is a bulwark of nuclear technology nonproliferation. This process issues or denies an export license based on the assessed intent of the buyer to use a transfer for proliferation purposes. The accuracy of any assessment and the efficacy of the process are generally unknown. Furthermore, the potential value of incorporating more context, or assessing risk over intent, is unknowable due to the lack of a flexible model of export licensing and the international nuclear technology economy. Agent-based modeling offers a methodology for exploring these issues and others. ACE modeling of export licensing can support four objectives: 1) advance understanding of the present licensing realm including process efficacy; 2) aid discovery of better licensing protocols through simulation of alternate licensing scenarios; 3 ) improve other methods and tools for non-proliferation analysis; and 4) enhance understanding of proliferation through alternate proliferation scenarios. ACE modeling may also support identification of suspect license applications, buyers, and sellers that differ from the norm.

ACE modeling could begin with efforts on two fronts. First, develop a relatively simple ACE model of the export licensing process that features countries as agents with input/output tables as data. This model would investigate the rise of an illicit nuclear technology economy, while learning about the applicability of ACE modeling to export licensing. On the second front, we would attempt ACE modeling of the export licensing realm with buyer, seller, and license reviewer agents, each agent with public, private, or protected access to subsets of methods and data (i.e., public, private, and protected methods and data) to understand better the specific licensing problem and the available, as well as necessary, information resources. To appreciate the applicability of ACE modeling across scales, individual agents may be grouped in larger agencies. Buyers and sellers may belong to market agents while license reviewers belong to a license review agency, with each of these composite agents also having public, private, and protected methods and data. Finally, all belong to the export licensing computational realm - an all-encompassing agent with its own public, private, and protected methods and data.

Public, private, and protected methods cover gathering, storing, and transmitting data, and include methods for changing methods. Public, private,, and protected data would contain information about 
buyers' and sellers' costs, profits and utilities, address books and communication links. The general activity flow in an agent-based modeling of export licensing would begin with defining the agents and then configuring with methods and initial data. The model then cycles with sellers posting offers, buyers seeking offers, and the markets matching buyers and sellers. Each match is submitted to export license review. Conditioned on the outcome of the license review, sellers and buyers engage (or not) in trade interactions and record trade outcomes. Finally, sellers, buyers, license reviewers, and other agents update their public, private, and protected methods and data based on their search, trade, and review experiences. Consequently, much can be learned about the licensing problem and resources, and their shortcomings, through an ACE modeling exercise. This would be true for ACE modeling to address the general nonproliferation problem, as well.

Because of the varying degrees of accuracy and completeness in an ACE model (expertise, data, etc.), the nature of the output is similarly varied - from purely qualitative insights to highly quantitative results at micro to macro scales. Nevertheless, ACE output can include a complete history of the simulated economy, such as the present state and history of each agent. The challenge is to define summary statistics informative about license evaluation or the license process, and develop the appropriate ACE model to generate the necessary ensemble of ACEs.

\subsection{Graphical Modeling and Analysis}

The knowledge discovery approach for discovering substructures in structural databases implemented in the Subdue system is described and the Subdue data-mining algorithm is evaluated in the following sections.

\subsubsection{Knowledge Discovery Approach}

Numerous approaches have been developed for discovering concepts in linear, attribute-value databases. Although many of the data collected today have an explicit or implicit structural component (e.g., spatial or temporal), only recently have discovery systems been designed to handle these types of

data. Current data-mining research focuses primarily on algorithms to discover sets of attributes that can discriminate data entities into classes, such as shopping or banking trends for a particular demographic group. These approaches experience difficulty when key concepts involve relationships between the data points. In contrast, we are developing data-mining techniques to discover patterns consisting of complex relationships between entities.

Export smuggling data are inherently structural. By examining the structure in terms of relationships between involved parties, flow of goods between countries, and other relationships, we may be able to discover common patterns that aid in detecting potential export dangers and smuggling attempts. The goal of this project was to apply graph-based structural data mining to discover patterns in this type of data.

We have introduced a method for discovering substructures in structural databases implemented in the Subdue system. In contrast with alternative approaches, Subdue is devised for general purpose automated discovery, concept learning, and hierarchical clustering (see Figure 5.18). Hence, the method can be applied to many structural domains. 


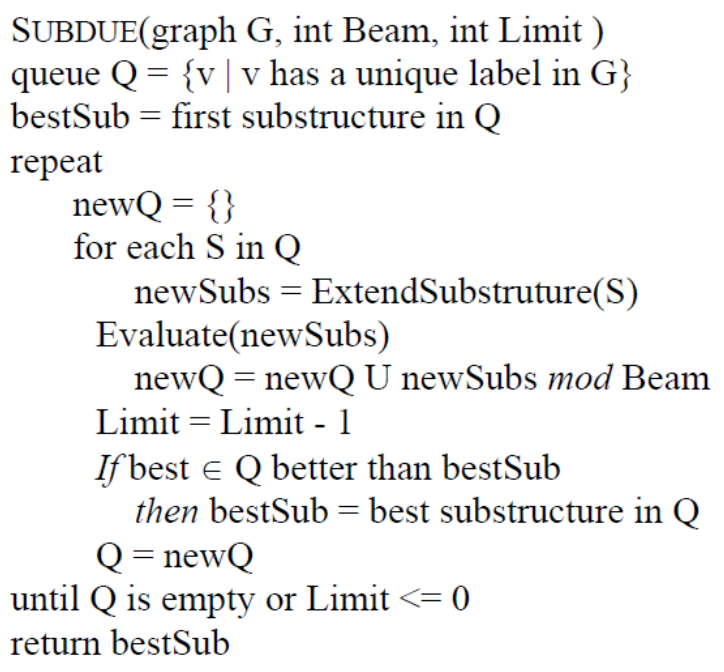

Figure 5.18. Subdue's Discovery Algorithm

Subdue accepts as input directed or undirected graphs with labeled vertices (nodes) and edges (links), and outputs graphs representing the discovered pattern or learned concept. Formally, Subdue uses a labeled graph $\mathrm{G}=(\mathrm{V}, \mathrm{E}, \mathrm{L})$ as both input and output, where $\mathrm{V}=\{\mathrm{v} 1, \mathrm{v} 2, \ldots, \mathrm{vn}\}$ is a set of vertices, $\mathrm{E}=$ $\{(\mathrm{vi}, \mathrm{vj}) \mid \mathrm{vi}, \mathrm{vj} \in \mathrm{V}\}$ is a set of edges, and $\mathrm{L}$ is a set of labels that can appear on vertices and edges. The graph $\mathrm{G}$ can contain directed edges, undirected edges, self-edges, and multi-edges. The input to Subdue can consist of one large graph or a collection of individual graphs, and in the case of supervised learning, the individual graphs are classified as positive or negative examples.

As an unsupervised algorithm, Subdue searches for a substructure, or subgraph of the input graph, that best compresses the input graph. Subdue uses a variant of beam search for its main search algorithm. A substructure in Subdue consists of a subgraph definition and all its occurrences throughout the graph.

Subdue uses a polynomial-time beam search for its discovery algorithm, as summarized in Figure 5.18. The initial state of the search is the set of substructures consisting of all uniquely labeled vertices. The search progresses by applying the ExtendSubstructure operator to each substructure in the current state. As its name suggests, it extends a substructure in all possible ways by a single edge and a vertex, or by only a single edge if both vertices are already in the subgraph. The resulting new substructures are ordered based on their compression (sometimes referred to as value) as calculated using the Minimum Description Length principle described below, and the top substructures (as determined by the beam) remain on the queue for further expansion.

The search terminates upon reaching a limit on the number of substructures extended, or upon exhaustion of the search space. Once the search terminates and Subdue returns the list of best substructures, the graph can be compressed using the best substructure. The compression procedure replaces all instances of the substructure in the input graph by single vertices, which represent the substructure definition. Incoming and outgoing edges to and from the replaced instances will point to or originate from the new vertex that represents the instance. The Subdue algorithm can be iterated invoked again on this compressed graph.

Subdue's search is guided by the Minimum Description Length (MDL) principle formalized in Equation (5), where $D L(S)$ is the description length of substructure $S$ being evaluated, $D L(G \mid S)$ is the 
description length of the graph as compressed by the substructure, and $D L(G)$ is the description length of the original graph. The best substructure is the one that minimizes this compression:

$$
\text { Compression }=\frac{D L(S)+D L(G \mid S)}{D L(G)}
$$

As an example, Figure 5.19 shows patterns that Subdue discovers in an example input graph and a compressed version of the graph. To allow for slight variations between instances of a discovered pattern (as is the case in Figure 5.19), Subdue applies an inexact graph match between the substructure definition and potential instances. Because instances of a substructure can appear in different forms throughout the database, Subdue computes the graph edit distance between two graphs and considers the substructure instance to be a match if the distance is less than a pre-defined threshold.

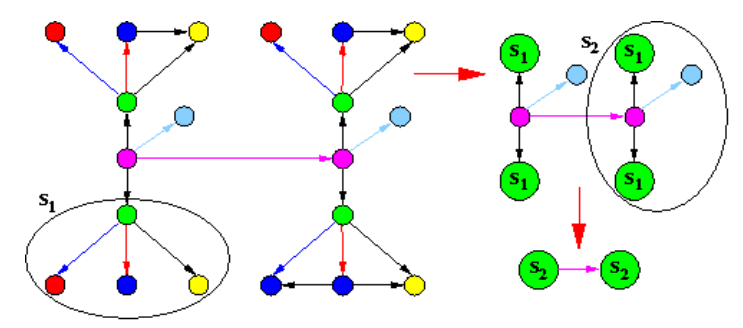

Figure 5.19. An Example of Subdue's Substructure Discovery Capability ${ }^{9}$

\subsubsection{Evaluation of the Data-Mining Algorithm}

To assess the ability of our Subdue graph-based data-mining algorithm to identify patterns in export data, we will analyze a similar database using this approach. For this task, we have targeted the Nuclear Smuggling database, which consists of reports on Russian nuclear materials smuggling. Very few export data are publicly available. However, the Nuclear Smuggling database contains many similar features and will offer a proof-of-concept for our proposed ideas.

The Chronology of Nuclear and Radioactive Smuggling Incidents is the basis of information for the Nuclear Smuggling data set. The data are based on open-source reporting, primarily World News Connection and Lexis-Nexis. The research from which the Chronology grew began in 1994 and continues through March 2000, containing 572 incidents. The incident descriptions in the Chronology are one entry per incident.

The data are presented as a chronology of the incidents in a relational database format. This format contains Objects, each of which has Attributes of differing types, with values input from source information or from the user. Entity objects contain fields such as location, material, organization, person, source, and weapon. Link objects are introduced when relationships are known between pairs of objects. The data set has over 40 relational tables, with each table containing as few as 2 or as many as 800 elements.

\footnotetext{
${ }^{9}$ The figure shows the discovered pattern $\left(\mathrm{S}_{1}\right)$ from the original graph, the substructure found during the second iteration $\left(S_{2}\right)$, and the final graph compressed using substructures $S_{1}$ and $S_{2}$.
} 
We are in the processing of converting the data to a graph representation. Once this is complete, we will perform the following types of analyses on the data:

- Use Subdue to look for commonly recurring patterns in the entire data set.

- Use Subdue to learn which events in an incident are related in order to construct larger knowledge structures that can be recognized as threats.

- Use Subdue to predict likely links between individuals, countries, and/or organizations.

The results of this analysis are expected to be consistent with expert evaluation of the data and Subdue's learning capability is expected to yield high link prediction accuracy. 



\subsection{Conclusions and Project Plan}

The outcome of this work suggests that we should develop a Bayes Net for micro-level analysis and continue to focus on Bayes Net, SD , and economic input/output models for assessing macro-level problems. Simultaneously, we need to develop metrics for assessing intent in export control, including the risks and consequences associated with all aspects of export control.

\subsection{Proposed Project Plan}

For this project, the team will work to accomplish the following tasks in the future:

- Continue development of the Bayes Net for micro-level analysis that integrates macro-level assessment results. Develop an additional report describing the model and associated inputs, and verify the model using case studies.

- Explore metric development for assessment of intent in export control. Include development of metrics for the risk and consequences associated with all aspects of export control. Consider feedback loops between indicators of proliferation intent and metrics focused on improving intent assessment.

- At the macro-level, two challenges will be investigated initially. At the country scale, the focus will be on the availability of supplier and consumer data. Some economic data are available at the country level. The required degree of granularity for assessment of country-level economics will also be investigated. The first step will be to build a general input/output model to represent the theoretical differences between a civilian nuclear power program and a nuclear proliferation program. Second, we will investigate whether collections of transactions capture more information about proliferation intent than individual transactions. We will continue to explore how multiple transactions can be modeled.

- Initially, we will focus on Bayes Nets, SD models, and economic input/output analysis as modeling tools.

- We will coordinate with existing and emerging issues and projects within NA-24. 



\subsection{Bibliography}

Alfarano, S., F. Wagner, and T. Lux. 2005. Estimation of Agent-Based Models: The Case of an Asymmetric Herding Model. Computational Economics, 26(1), pages 19-49. Available at: http://www.bwl.uni-kiel.de/gwif/files/papers/alfarano_estimation.pdf.

Armstrong, JS (ed.). 1985. Long Range Forecasting, 2nd Edition. Available at: http://www.forecastingprinciples.com/Long-Range\%20Forecasting/contents.html. Accessed September 2008.

Armstrong, JS (ed.). 2001. Principles of Forecasting. Kluwar Acedemic Publishers, Norwell, Massachusetts.

Axelrod R. 2003. "Advancing the Art of Simulation in the Social Sciences." Japanese Journal for Management Information System, special issue on agent-based modeling 12(3).

Axtell R, Axelrod R, Epstein JM, and MD Cohen. 1996. "Aligning Simulation Models: A Case Study and Results." Computational and Mathematical Organization Theory 1(1):123-141.

Bain, L. J., and M. Engelhardt. 1992. Introduction to Probability and mathematical Statistics, Duxbury, Thomson Learning.

Bak, P. C. Tang, and K. Wiesenfeld. 1988. "Self-organized criticality." Physical Review A 38:364-374.

Barabasi, A. L. 2002. Linked: The New Science of Networks. Perseus Publishing, Cambridge, MA.

Barlas, Y. 1996. "Formal aspects of model validity and validation in system dynamics." System Dynamics Review 12( 3)183-210.

Begovic, M. 2001. In The Electric Power Engineering Handbook, edited by L. L. Grigsby, Power System Protection (CRC Press, Boca Raton, Florida), 9:41.

Berger, J. O. 1985. Statistical Decision Theory and Bayesian Analysis. 2nd ed. Springer-Verlag, New York, NY.

Blackman, A. 1997. "The Economics of Technology Diffusion: Implications for Greenhouse Gas Mitigation in Developing Countries. Resources for the Future, Climate Issues Brief \#5.

Boisso, D and M Ferrantino. 1997. "Economic Distance, Cultural Distance, and Openness in International Trade: Empirical Puzzles.” Journal of Economic Integration 12 (4), 456-484

Bonabeau E. 2002. "Agent-based modeling: methods and techniques for simulating human systems." PNAS 99(3):7280-7287.

Brown, R. G., and P.Y.C. Hwang. 1997. Introduction to Random Signals and Applied Kalman Filtering. 3rd ed. John Wiley \& Sons, Hoboken, NJ. 
Carlson, J. M., and J. Doyle. "Highly Optimized Tolerance: A Mechanism for Power Laws in Designed Systems." To be published, Phys. Rev. E.

Challet, D., M. Marsili, and R. Zecchina. 2000. "Statistical Mechanics of Heterogeneous Agents : Minority Games.” Phys. Rev. Lett. 84:1824, preprint cond-mat/9904392.

Chen, M.-H., and Q.-M. Shao. 1999. "Monte Carlo Estimation of Bayesian Credible and HPD Intervals." Journal of Computational and Graphical Statistics. 8:69-92.

Clupeoids. Available at: http://www.humboldt.edu/ ecomodel/clupeoids.htm.

Coon, RC, FL Leistritz, TA Hertsgaard, and AG Leholm. 1985. The North Dakota Input-Output Model: A Tool for Analyzing Economic Linkages. Agricultural Economics Report No. 187, North Dakota State University, Fargo, North Dakota.

CORMAS - Ressources naturelles et simulations multi-agents. Available at: http://cormas.cirad.fr/.

Fagiolo, G, C Birchenhall, and P Windrum (eds). 2007. "Special Issue on "Empirical Validation in Agent-Based Models." Computational Economics 30:3.

Ford, A. 1999. Modeling the Environment: An Introduction to System Dynamics Modeling of Environmental Systems. University of Chicago Press, Chicago, Illinois.

Forrester, JW. 1991. "System Dynamics and the Lessons of 35 Years.” In The Systemic Basis for Policy Making in the 1990s, KB De Greene (ed.), Massachusetts Institute of Technology, Boston, Massachusetts.

Forrester, JW. 1969. Urban Dynamics. The MIT Press, Boston, Massachusetts.

Fukuchi, T, and M Satoh. 1999 "Technological Distance Between Indonesia and Brazil: Comparative Study of Technical Input Structure,” Developing Economies, XXXVII-3 pp 253-274

GeNIe Tutorials. 2008. Decision Systems Laboratory of the University of Pittsburgh. Available at: http://genie.sis.pitt.edu/wiki/GeNIe_Documentation. Accessed December 2008.

Gilks, W. R., S. Richardson, and D. J. Spiegelhalter. 1996. Markov Chain Monte Carlo in Practice. Chapman and Hall/CRC., Boca Raton, Florida.

Hafez, MM. 2003. Why Muslims Rebel: Repression and Resistance in the Islamic World. Lynne Riener Publishers, Boulder, Colorado.

Heuer, RJ. 1999. Psychology of Intelligence Analysis. Center for the Study of Intelligence, Central Intelligence Agency. Available at: https//www.cia.gov/csi/books/19104. Accessed 8/21/2008.

Hoffman, RB, and JN Kent. 2005. "Design for Commodity-by-Industry Interregional Input-Output Models." Chapter 12 in Regional and Interregional Studies. Available at: http://www.whatiftechnologies.com/publication/. Accessed 8/21/2008

Hume, D. 1748. Enquiry Concerning Human Understanding. 
Hürzeler, M, and HR Künsch. 1998. "Monte Carlo Approximations for General State-Space Models." Journal of Computational and Graphical Statistics 7(2):175-193.

Huse, G, S Railsback, and A Fernø. 2002. "Modeling changes in migration patterns of herring: collective behaviour and numerical domination." Journal of Fish Biology 60:571-582.

Jensen, FV, and TD Nielsen. 2007. Bayesian Networks and Decision Graphs, 2nd edition. Springer, New York.

Judd, KL. 2006. "Computationally Intensive Analyses in Economics." Handbook of Computational Economics. Vol. 2: Agent-Based Computational Economics. L Tesfatsion and KL Judd (eds.), Handbooks in Economics Series, North-Holland, Amsterdam.

Kitagawa, G. 1996. "Monte Carlo Filter and Smoother for Non-Gaussian and Nonlinear Sate Space Models." Journal of Computational and Graphical Statistics. 5(1):1-25.

Law, AM. 2007. Simulation Modeling and Analysis, Fourth Edition. McGraw-Hill Higher Education.

Lehman, E. L., and G. Casella. 1998. Theory of Point Estimation. Springer-Verlag New York.

Liew, CJ. 2000. "The dynamic variable input-output model: An advancement from the Leontief dynamic input output model." The Annals of Regional Science 34:591-614

Löfgren, H and S Robinson. 1999. "Spatial Networks in Multi-Region Computable General Equilibrium Models.” TMD Discussion Paper NO. 35, Trade and International Food Policy Research Institute, Washington, D.C. Available at: http://www.ifpri.org/divs/tmd/dp/papers/tmdp35.pdf. Accessed $8 / 15 / 2008$.

MABEL at Purdue. Available at: http://ltm.agriculture.purdue.edu/mabel/overview.htm.

Macal, CM and MJ North. 2006. "Tutorial on agent-based modeling and simulation part 2: How to model with agents." Proceedings of the 2006 Winter Simulation Conference (IEEE) 73-83.

McCauley, C and S Moskalenko. 2008. "Mechanisms of Political Radicalization: Pathways Toward Terrorism”. Terrorism and Political Violence, Volume 20, Issue 3 July 2008, pages 415 - 433.

Manning, CD and Schütze, H. 1999. Foundations of Statistical Natural Language Processing. Cambridge, MA: MIT Press.

Marks, R. 2008. "Validating Simulation Models: A General Framework and Four Applied Examples." Computational Economics (in press).

Marriott, J. 2007. “An Electricity-focused Economic Input-output Model: Life-cycle Assessment and Policy Implications of Future Electricity Generation Scenarios.” Thesis, Carnegie Mellon University, Pittsburgh, Pennsylvania. Available at: http://wpweb2.tepper.cmu.edu/ceic/theses/Joe_Marriott_PhD_Thesis_2007.pdf. Accessed 9/11/2008.

MASON Multiagent Simulation Toolkit. Available at: http://cs.gmu.edu/ eclab/projects/mason/. 
McBurney, PJ and TR Payne. 2008. "European co-ordination action for agent-based computing." Information Society Technologies Program. European Commission. United Kingdom. www.agentlink.org

Meadows, DH, J Randers, Dennis L. Meadows W. 2004. The Limits to Growth: The 3-Year Update. Chelsea Green Publishing Company, White River Junction, Vermont.

Mickle, MH. 1998. "Structure, Use, and Validation of the IEUBK Model.” Environmental Health Perspectives Supplements 106(S86):1531-1534.

Midgley, D, Marks R and D Kunchamwar 2009. "The Building and Assurance of Agent-Based Models: An Example and Challenge to the Field." (in press) Journal of Business Research.

Moore, A., and M. S. Lee. 1998. "Cached sufficient statistics for efficient machine learning with large datasets." Journal of Artificial Intelligence Report 8:67-91.

Morstein, JJ, and WD Perry. 2000. "Commercial Nuclear Trading Networks as Indicators of Nuclear Weapons Intentions.” The Nonproliferation Review/Fall-Winter 2000. pp. 75-91

NWT Bureau of Statistics. June 2006. "NWT Input-Output Model - An Overview." Government of the Northwest Territories, Canada.

Pearl, J. 2000, Causality: Models, Reasoning and Inference. Cambridge University Press, New York.

Post, J, K Ruby, and E Shaw. 2002. "The Radical Group in Context: 1. An Integrated Framework for the Analysis of Group Risk for Terrorism.” Studies in Conflict \& Terrorism 25(2):73-100.

Ptahsne, M, and A Gann. 2002. Genes and Signalling, Cold Spring Harbor Laboratory Press, New York.

Qudrat-Ullah, H. 2005. "Structural Validation of System Dynamics and Agent-Based Simulation Models." Proceedings, 19th European Conference on Modelling and Simulation (ECMS). Y. Merkuryev, R. Zobel, and E. Kerckhoffs (editors).

Robert, C. P., and G. Casella. 1999. Monte Carlo Statistical Methods. Springer.

Roberts N, DF Andersen, RM Deal, MS Garet, and WA Shaffer. 1983. Introduction to Computer Simulation: A System Dynamics Modeling Approach. Productivity Press, Portland, Oregon.

Sanfilippo, A, J Schryver, P Whitney, E Augustenborg, G Danielson, and S Thompson. 2009. "VIM: A Platform for Violent Intent Modeling." In H Liu (ed.) Social Computing, Behavioral Modeling, and Prediction II, Springer, USA.

Sanfilippo, A, AJ Cowell, S Tratz, A Boek, AK Cowell, C Posse and L Pouchard. 2007. "Content Analysis for Proactive Intelligence: Marshaling Frame Evidence." In Proceedings of the AAAI Conference, Vancouver, BC, Canada.

Sanfilippo, A, L Franklin, S Tratz, G Danielson, N Mileson, R Riensche, and L McGrath. 2008. “Automating Frame Analysis.” In H Liu, J Salerno, and M Young (eds.), Social Computing, Behavioral Modeling, and Prediction, pp. 239-248. Springer, New York. 
Sani, F. 2005. "When subgroups secede: Extending and refining the social psychological model of schisms in groups." Personality and Social Psychology Bulletin,31:1074-1086.

Santner, TJ, BJ Williams and WI Notz. 2003. The Design and Analysis of Computer Experiments. Springer Series in Statistics. 283pp. ISBN: 978-0-387-95420-2.

Senge, PM. 1990. The Fifth Discipline: The Art and Practice of the Learning Organization. Doubleday Currency, New York.

Shafer, Glenn, 1996. The Art of Causal Conjecture. The MIT Press, Cambridge Massachusetts.

Solka, JL, EJ Wegman, CE Priebe, WL Poston, and GW Rogers. 1998. "A Method to Determine the Structure of an Unknown Mixture Using the Akaike Information Criterion and the Bootstrap." Statistics and Computing 8:177-188.

Solka, JL, WL Poston, and EJ Wegman. 1995. "A Visualization Technique for Studying the Iterative Estimation of Mixture Densities.” Journal of Computational and Graphical Statistics 4(3):180-197.

SWARM (Main Page). Accessed Mar. 2005. Available at: http://www.swarm.org/wiki/Main Page.

Tanner, M. A. 1996. Tools for Statistical Inference: Methods for the Exploration of Posterior Distributions and Likelihood Functions. Third ed. Springer-Verlag, New York.

ten Raa, T. 2005. "Using Input Output Models for Policy Making." Tilburg University, Tilburg, The Netherlands. Available at:

http://www.eerc.kiev.ua/events/conferences/workshop $06 \quad 12$ 2005/Thijs\%20Ten\%20Raa\%20Handouts. doc. Accessed August 15, 2008

Tertrais, B. 2007. 'Not a 'Wal-Mart', but an 'Imports-Exports Enterprise': Understanding the Nature of the A.Q. Khan Network." Strategic Insights 6(5).

Thornton, BS and RM Sorli. 1982. "Validation problems and technological change in an input-output model." International Journal of Mathematical Education in Science and Technology, 13(6):663-679.

Troitzsch, KG. 2004. "Validating Simulation Models." Proceedings of the 18th European Simulation Multiconference, SCS Europe.

United Nations. 2008. "Publications : National Accounts Statistics: Main Aggregates and Detailed Tables, 2005 (PDF Version) Part I, II and III, Forty-seventh issue." http://unstats.un.org/unsd/pubs/gesgrid.asp?electronic=yes. Last Updated: Unknown. Date Accessed: 9/11/2008.

Wahba, G. 1990. "Spline Models for Observational Data." Philadelphia, US: Society for Industrial and Applied Mathematics (CBMS-NSF regional Conference Series in Applied Mathematics; 59).

Werker, C, and T. Brenner. 2006. "A Practical Guide to Inference in Simulation Models." Working Paper 0602. Papers on Economics \& Evolution. Max Planck Institute of Economics, Evolutionary Economics Group, Jena, Germany. 
Wilenski, U and W Rand. 2007. "Making Models Match: Replicating an Agent-Based Model.” Journal of Artificial Societies and Social Simulation (JASSS). 10:4(2).

Willingham, CE, Jr. 2011. "Nuclear Fuel Cycle and Weapons Development Process Chart, September 2010 Ver 2.3.” PNNL-SA-79405, Pacific Northwest National Laboratory, Richland, Washington.

Windrum, P, Fagiolo G and A Moneta. 2007. "Empirical Validation of Agent-Based Models:

Alternatives and Prospects." Journal of Artificial Societies and Social Simulation. 2:2(8).

Winker, Peter and Gilli, Manfred. 2001. Indirect Estimation of the Parameters of Agent Based Models of Financial Markets. FAME - International Center for Financial Asset Management and Engineering.

Wood, TW, BA Reichmuth, MR Weimar, RF O'Brien, and MD Milazzo. 2006. "Identification of High Risk Intermediaries in Global Networks Transferring Sensitive Technology and Information." In Proceedings of the 2006 IAEA Symposium on International Safeguards: Addressing Verification Challenges. PNNL-SA-51706

Wood TW, SJ Kreyling, SE Thompson, and CE Willingham Jr. 2008. Information Environment for DOE Nuclear Supply and Transfer Assessment. PNNL-17798, Pacific Northwest National Laboratory, Richland, Washington. 
Appendix A

\section{Annotated Bibliography}





\section{Appendix A}

\section{Annotated Bibliography}

Axelrod R. 2003. "Advancing the Art of Simulation in the Social Sciences." Japanese Journal for Management Information System: Special Issue on Agent-Based Modeling 12(3):1-19.

Utility: Moderate. Provides advice about agent-based simulation research, focusing on the programming, and analyzing and communicating the results.

Theme: Axelrod opens with a section selling the virtues of agent-based simulation, followed by practical high-level advice about agent-based modeling. Replicating other people's simulations gets special emphasis, with examples of the procedures and difficulties involved in the process of replication.

Axtell R. 2006. “Agent-Based Computing in Economics.” Slide presentation, Center on Social and Economic Dynamics, The Brookings Institution, Washington, D.C.

Utility: Low-Moderate. Introduction with many good leads.

Theme: Broad introduction to agent-based modeling with motivation, history, competing approaches, applications, and critique.

Becker R, J Haltiwanger, R Jarmin, S Klimek, and D Wilson. 2005. "Micro and Macro Data Integration: The Case of Capital." Center for Economic Studies, U.S. Bureau of the Census.

Becker et al. (2005) develop a hybrid approach to improving consistency between bottom-up (micro) and top-down (aggregate or macro-level) estimation methods for macroeconomic accounting of capital stocks. They indicate that aggregate capital stock and flows are a supply-side measure, meaning that the information is obtained from suppliers of capital stocks. The paper documents the significant differences between approaches to the measurement of capital from both the aggregate and the micro level. They indicate that the measurement of production, imports, and exports provides a reasonably accurate view of capital stocks and flow. It is, however, much more difficult to allocate the stocks and flows to the different areas of consumption: industry, personal and government consumption, and fixed investment. The most significant assumption is the allocation of the stocks according to the proportion of employment in each industry. They suggest that allocations of capital stocks need to reflect the lumpiness of stock purchases, the entry and exit of firms, and the contributions of young versus mature firms; all affect making the allocations from a micro and macro level consistent. Thus, this paper indicates a process by which data will need to be processed in order to disaggregate macro-level data to understand the microlevel requirements of estimating dual-use commodity requirements in an economy. 
BIS Export Enforcement. 2008. “Major Cases List.” U.S. Department of Commerce. Accessed November 18, 2008, at http://www.bis.doc.gov/complianceandenforcement/majorcaselist.pdf .

This paper lists summaries of major cases of export violations. The broad categories in this paper are

- WMD and Missile Proliferation

- Terrorism/State Sponsors of Terrorism

- Unauthorized Military Use

- Other Dual-Use

- Deemed Exports/

This paper is a good domain-related reference and should be specifically referenced in the context of the examples.

Chen J and G Sun. 2001. Modeling Methods of Qualitative Models for Macroeconomic Forecasting. Department of Management Science and Engineering, School of Economics and Management, Tsinghua University, Beijing, China. Accessed November 18, 2008, at http://www.iss.ac.cn/iss/conferences/sinojapan2001/Chenjian.pdf.

This presentation contains a macro/micro view of economic modeling. The fundamental approach is to generate a formal mathematical representation of qualitative relationships and leverage those to construct that relationship. Although the presentation does not report on any extensive studies using the methodology, the approach is intriguing and can be related to more traditional quantitative representations used in macro-economics.

Coon R, F Leistritz, T Hertzgaard, and A Leholm. 1985. The North Dakota Input-Output Model: A Tool for Analyzing Economic Linkages. Agricultural Economics Report 187, Department of Agricultural Economics, North Dakota State University, Fargo, North Dakota.

Coon et al. (1985) explain the principles of the North Dakota input-output model and how to interpret results from research undertaken using the model. Input-output models describe the interdependencies between industrial sectors of a country's or region's economy. The current North Dakota model delineates 17 standard industrial sectors following the Standard Industrial Classification (SIC) nomenclature. Following standard input-output model approaches, the report describes a three-step approach to developing the coefficients required to build the model. In the first step, a transactions table is developed showing each industry's purchases from all other sectors in which columns denote industries and rows indicate commodities. In the second step, input-output coefficients are developed from the transactions tables as fractions of each commodity as a fraction total of requirements for an industry. In the third step, these industry requirements are converted to determine the direct and indirect components of each industry, and output for final demand. Summing the column totals provides the gross receipts multipliers. Strict input-output models assume no technology change and no economies or diseconomies associated with production. 
Dawid H. 2008. "Agent-Based Models for Economic Policy Design: Introduction to the Special Issue." Journal of Economic Behavior \& Organization 67:351-354

Utility: High. Although generally lacking specific details (mathematics), the special issue provides broad, useful guidance.

Theme: Dawid notes the aim of this special issue is to focus on the normative, rather than the descriptive, potential of the agent-based approach, in particular on the usefulness of ACE models for the evaluation and design of economic policy measures. The collection addresses topics from very specific policy design questions to classic general issues in the policy debate and represents a selection of work presented in July 2005 at the workshop, "Agent-Based Models for Economics Policy Design," at the Center for Interdisciplinary Research (ZiF) at Bielefeld University. The papers span policy questions, from quite general to very specific, and highlight different approaches to deal with ACE validation and robustness checks. The papers deal with 1) industrial policy and market design, 2) the value chain in multi-tier electricity markets, 3) bidding behavior in different market environments, and 4) the effects of fiscal policy measures in different parts of the economy (in particular, the impact of several anti-crime policies).

Engle E. 2004. “Agent Models of Political Interaction.” Journal of Economic Dynamics \& Control 24:679-702

Utility: Low. A general discussion of social political modeling using game theory with few details.

Theme: The paper is about agent modeling in a social-political context and emphasizes game theory. It is divided into three sections: 1) a description of emergence in social-political science; 2) a description of relevant computer science game theory concepts and examples of implementations; and 3) a brief, vague description of the author's game theory RISK implementation. The paper is about philosophy and guiding principles and offers minimal useful details.

Jager SM. 2007. On the Uses of Cultural Knowledge. Strategic Studies Institute of the U.S. Army War College, Carlisle, Pennsylvania.

The report articulates recent thinking in the U.S. Military on the value of cultural information for effectively addressing and winning the war on terror. The report outlines what are essentially hypotheses for the role of culture in addressing the threat of terrorism.

Kelle U. 2001. "Sociological Explanations between Micro and Macro and the Integration of Qualitative and Quantitative Methods.” Forum: Qualitative Social Research 2(1):19. 
Kelle (2001) argues that qualitative and quantitative method designs need to be integrated in social research. Kelle contrasts three methods of triangulation using examples to explain the triangulation metaphor. The triangulation metaphor provides a way to explain sociological phenomena through mutual validation, as integration of different perspectives, or as implied by its trigonometric definition. In mutual validation, the qualitative and quantitative approaches can complement and, therefore, lead the researcher to the same conclusion. Or one could conclude that one method provided no further valuable information. He, however, rejects this as not useful, as one does not know the outcome until analysis of both quantitative and qualitative methods has drawn conclusions about the research. His examples provide evidence that complementary analysis of sociological events can provide significantly different results if qualitative and quantitative methods are not included. He found that structural data on the access to training provided good quantitative relations in particular occupations and on the gender of the respondent. However, when looking at mechanics and the drive to further education, more qualitative information was needed to explain the phenomena. Only when qualitative data about life habits were added, did the information on occupational careers make sense. The qualitative data explained the difference by finding the difference in how the different occupations looked at work. The bankers found variation in work valuable, while craftsmen found work to be only ends to the means. In addition, knowledge about the German education system provided additional qualitative information that would not be known without growing up in that system. Only by knowing the structure of education in Germany would you know that bankers have already passed the exam to enter university, while mechanics go to trade school and must take additional classes in order to reach university. Kelle indicates that validation by different methods increases the validity of the hypothesis. In another example, he shows that knowledge about women's perspectives and motives was not enough to explain career choices. It was also necessary to look at structural information, such as potential wages for the women, in understanding their decisions to re-enter the workforce. Both cases indicate that both the qualitative and quantitative methods were required to draw the appropriate conclusions about the sociological phenomena. In his last example, he showed how, without the qualitative information to invalidate the conclusions of the quantitative data, the wrong conclusions about the sociological phenomena would have been drawn. For this illustration, he used the rigid East German structure of education and occupation. Most people would conclude that individuals did not have a choice, but he found through interviews that individuals who understood how the system worked could actually work the system to obtain the outcome they desired. His research showed through example that without both qualitative and quantitative methods, the wrong conclusions could be drawn if a researcher were relying on only one method or the other. He also found that in some cases, wrong conclusions could be drawn without the qualitative data. This research indicates that given the sociological implications associated with the surreptitious approaches to obtaining nuclear technology, some part of the methodology needs to include the qualitative underpinnings and mindsets of the individuals and states trying to obtain nuclear technology.

LeBaron B. 1999. "Agent-Based Computational Finance: Suggested Readings and Early Research.” Journal of Economic Dynamics \& Control 24:679-702.

Utility: Moderate. Broad mini-tutorial with numerous pre-2000 references provides good foundational introduction across the range of agent-based methodology development from initial model definition through verification, validation, and interpretation. 
Theme: LeBaron summarizes in detail six early seminal papers in agent-based computational finance (ACF) with references to many others. Of note is the modest mathematical detail that is lacking in most other ACE papers.

Markose SM. 2007. "Advances in Experimental and Agent-Based Modelling: Asset Markets, Economic Networks, Computational Mechanism Design and Evolutionary Game Dynamics." Journal of Economic Dynamics \& Control 31:1801-1807

Utility: Low. From the introduction by Markose, the special issue does not appear to offer substantial information directly applicable to developing or refining an agent-based nuclear technology economic methodology. The articles may provide helpful overall guidance and useful hints.

Theme: Markose pens the opening editorial for a special issue of Journal of Economic Dynamics \& Control that primarily documents work presented at the "Tenth Workshop on Economic Heterogeneous Interacting Agents (WEHIA 2005)" hosted by the Centre for Computational Finance and Economic Agents of the University of Essex, United Kingdom. The editorial introduces the issue's papers - a sampling from agent-based computational economics (ACE) and Economic Science for Heterogeneous Interacting Agents (ESHIA). The major themes of the paper collection are the replication and analysis of markets and other socioeconomic environments with interacting, often heterogeneous, artificial and human agents.

Onisko A, M Druzdzel, and H Wasyluk. 2001. "Learning Bayesian Network Parameters from Small Data Sets: Application of Noisy-OR Gates." International Journal of Approximate Reasoning 27(2):165-168.

This paper describes how data can be used to estimate the conditional probability table (CPT) in a Bayes Net. The particular idea used is using a reduced parameter representation of the CPT, in particular a Noisy-OR structure, results in increased accuracy of the resulting CPT while training using small data sets. Note: this idea is consistent with the lessons of parameter estimates in statistics - that accepting some potential bias in an estimator can result in overall improvements in accuracy. The particular example studied is the medical diagnosis domain.

This paper is a good reference to add for the Bayes Net modeling section.

Reynolds CW. 1987. "Flocks, Herds, and Schools: A Distributed Behavioral Model." In the Proceeding of SIGGRAPH '87, MC Stone (ed.), Computer Graphics 21(4):25-34.

Utility: High. "Boids" is a simple, accessible agent-based model that would be useful for development of statistical estimation, verification, and validation methodologies.

Theme: This paper explores simulation of individual birds to generate a flock and is an elaboration of a particle system, with the each simulated bird being a particle. The aggregate motion of the simulated 
flock is created by a distributed behavioral model much like that at work in a natural flock; the birds choose their own course. Each simulated bird is implemented as an independent actor that navigates according to its local perception of the dynamic environment, the laws of simulated physics that rule its motion, and a set of behaviors programmed into it by the "animator." The aggregate motion of the simulated flock is the result of the dense interaction of the relatively simple behaviors of the individual simulated birds.

Skyrms B and R Pemantle. 2000. “A Dynamic Model of Social Network Formation.” Proceedings of the National Academy of Sciences 97(16):9340-9346.

An agent modeling system is mathematically analyzed to determine which stable structures emerge. The agents are homogenous, but eventually some structures of relationships emerge.

This paper is relevant for the Agent modeling section.

Tesfatsion L. 2002. "Agent-Based Computational Economics: Modelling Economies as Complex Adaptive Systems." Preprint submitted to Elsevier Science.

Utility: Low. Useful general introduction to the main objectives and defining characteristics of the ACE methodology.

Theme: Tesfatsion defines and discusses agent-based computational economics (ACE) - the computational study of economies modeled as evolving systems of autonomous interacting agents. She outlines the main objectives and defining characteristics of the ACE methodology and discusses several active research areas.

Tesfatsion L. 2006. “Agent-Based Computational Economics: A Constructive Approach to Economic Theory." In Handbook of Computational Economics, Volume 2: Agent-Based Computational Economics, L Tesfatsion and KL Judd (eds.), Elsevier/North-Holland (Handbooks in Economics Series).

Utility: Moderate to High. Useful general introduction to the main objectives and defining characteristics of the ACE methodology.

Theme: Paper describes the economic modeling problem and then offers agent-based computing as a possible solution. Economies are complicated systems encompassing micro behaviors, interaction patterns, and global regularities. Studies of economic systems must handle difficult real-world aspects such as asymmetric information, imperfect competition, strategic interaction, collective learning, and possibly multiple equilibria. This chapter explores the potential advantages and disadvantages of ACE for the study of economic systems. General points are concretely illustrated using an ACE model of a two-sector decentralized market economy. Six issues are highlighted: 1) constructive understanding of production, pricing, and trade processes; 2) the essential primacy of survival; 3) strategic rivalry and market power; 4) behavioral uncertainty and learning; 5) the role of conventions and organizations; and 
6) the complex interactions among structural attributes, institutional arrangements, and behavioral dispositions.

Tesfatsion L. 2006. "Agent-Based Computational Economics: Modeling Economies as Complex Adaptive Systems." Slide presentation, Department of Economics, Iowa State University, Ames, Iowa.

Utility: Moderate to High. Useful introduction to the motivation, main objectives, and defining characteristics of the ACE methodology with useful (sparsely) detailed examples.

Theme: Tesfatsion defines and discusses agent-based computational economics (ACE) - the computational study of economies modeled as evolving systems of autonomous interacting agents. She outlines the motivation, main objectives, and defining characteristics of the ACE methodology. She illustrates ACE with several examples, although details are few.

Tesfatsion L. 2008. "Agent-Based Computational Economics: Growing Economies from the Bottom Up.” Accessed November 19, 2008, at http://www.econ.iastate.edu/tesfatsi/ace.htm

Utility: High. Excellent source for general and specific information and resources about agent-based computional economics, including examples and tutorials.

Theme: Tesfatsion established and maintains this website devoted to agent-based computational economics (ACE). This site introduces ACE and provides access to useful ACE introductory, research, teaching, and software resources. The agent software RePast/RePastJ is promoted with links to examples, demonstrations, and study guides. The site maintains current links to other useful websites about the development and use of agent-based models.

Tesfatsion L. 2008. “Agent-Oriented Programming: Intro.” Slide presentation, Department of Economics, Iowa State University, Ames, Iowa.

Utility: Moderate to High. ACE programming introduction with many good leads.

Theme: Somewhat in-depth ACE programming introduction emphasizing ACE computational laboratories using The Trade Network Game Lab (TNG) Laboratory as an example.

Tesfatsion L and KL Judd (eds.). 2006. Handbook of Computational Economics, Vol. 2: Agent-Based Computational Economics. Elsevier/North-Holland (Handbooks in Economics Series).

Utility (no/micro/macro): High. The book's name says it all. 
Theme: The ACE handbook is divided into 16 chapters, 6 shorter perspective essays, and an appendix. Chapter 1, by L Tesfatsion, discusses the ACE approach to the study of economic systems and contrasts this approach with more standard equilibrium approaches. In Chapter 2, K Judd focuses on the problems of determining and communicating the economic content of the results of computationally intensive research and the trade-offs between standard approaches and computational methods. Chapter 3, by T Brenner, discusses the key role played in ACE models by learning agents and critically surveys a wide variety of possible agent learning representations. In Chapter 4, J Duffy examines the potential synergies between experiments conducted with human subjects and experiments conducted with computational agents, with emphasis on empirical validation issues. The determination of agent interaction patterns is a basic foundation for all ACE models. In Chapter 5, A Wilhite undertakes a series of experiments to explore how bilateral trading and other forms of economic interactions are influenced when conducted within alternative types of networks (e.g., a small-world network). N Vriend extends this focus in Chapter 6 by considering how ACE researchers have modeled the endogenous formation of interaction networks. In the latter models, agents have some degree of choice regarding not only how to behave in any given interaction but also with whom to interact and with what regularity. In Chapter 7 , HP Young presents and concretely illustrates a rigorous method for analyzing the long-run behavior of systems constituting large numbers of interacting agents with widely differing characteristics. Chapters 8 and 9 provide extensive surveys of financial market research in which the endogeneous heterogeneity of dynamic investment behavior appears to be critically important for the explanation of observed regularities in financial time series. In Chapter $8, \mathrm{C}$ Hommes focuses on relatively simple financial market models that are at least partly tractable by analytic methods and that are being used as benchmarks in support of more complex ACE modeling efforts. In contrast, B LeBaron in Chapter 9 focuses on ACE financial market studies for which the complexity of the models requires the intensive use of computational tools. Technological change and innovation concern the generation and diffusion of new knowledge, technologies, and products. In Chapter 10, H Dawid discusses the current and potential contributions of the ACE modeling approach to this difficult topic area. In Chapter 11, M Chang and J Harrington survey a wide variety of organization models, including models of multi-agent firms, multiplant manufacturers, and retail chains. They develop their chapter around a set of research questions common to the organization literature, comparing and contrasting traditional and agent-based modeling approaches and highlighting new insights afforded by the latter approach. In Chapter 12, R Marks first reviews in general terms the manner in which ACE models with strategic learning agents have been used to evaluate market designs from a dynamic perspective. He then highlights ten papers that exemplify recent progress in this topic area, with a particular emphasis on the evaluation of electricity market designs. Chapter 13, by J Mackie-Mason and M Wellman, also addresses market design issues. In contrast to Marks, however, the authors focus their attention on automated markets with software trading agents. Chapters 14 and 15 focus on issues of importance to economists for which political concerns are paramount. In Chapter 14, K Kollman and S Page critically survey a range of agent-based models developed by economists and political scientists to address collective action problems, pie-splitting problems, electoral competitions, and security and communal stability issues at both the national and subnational levels. In Chapter 15, M Janssen and E Ostrom survey ACE research addressing the governance of systems comprising social and biophysical agents. In Chapter 16, C Dibble discusses the potential of computational laboratories for facilitating the design and exploratory analysis of agent-based models with spatial aspects. Illustrative examples include spatial small-world network models, social norm diffusion models, and epidemiology models for the control of infectious diseases. Finally, six essays offer shorter perspectives on agent-based modeling. 
Tertrais B. 2007. "Not a 'Wal-Mart', but an 'Imports-Exports Enterprise': Understanding the Nature of the A.Q. Khan Network." Strategic Insights 6(5).

Tertrais (2007) examines the A.Q. Khan nuclear import/export schemes that were used to obtain the necessary nuclear technology to enable Pakistan to develop nuclear bomb capabilities and then export that technology to North Korea, Iran, and Libya. According to Tertrais, most of the equipment was obtained from firms in Europe with help from the United States and China. The original network was started by Munir Khan, not A.Q. Khan. M. Khan's primary operative was SA Butt, who Pakistan assigned to various embassies. A.Q. Khan joined the network in 1976 and became a major operative. The network included several elements, including systematic use of its embassies. The network avoided controls by buying component parts, not assemblies. In addition, they learned to reproduce parts; used multiple buyers, intermediaries, and front companies; and falsified end-user certificates. They also "hid" critical items in a long list of otherwise useless items. They also limited their purchases so that they could learn to reproduce them. Iraq used similar methods in the early 1980s. The import schemes were successful not only because they were fairly sophisticated but because western firms actively cooperated in selling the Pakistanis the technology. Pakistan also used Europe's liberal trade policies to hide the end destination of their imports. Additionally, European countries were not entirely enthused about nonproliferation efforts including resistance to the United States' political pressure. Some countries were actively promoting exports, which was in direct contradiction to export control. Tertrais blames this on "denial, delusion and defiance." Tertrais also traces how Pakistan exported their nuclear technology to Iran, North Korea, and Libya. Intermediary countries Pakistan used in its import/export of nuclear technology included the United Arab Emirates, Malaysia, Turkey, and South Africa. The nuclear exports were probably driven by greed. It appears that A.Q. Khan did not always have the backing of the Pakistani government, although he may have felt covered by his relationships with government officials. In some cases, nuclear exports were a quid pro quo for assistance that Pakistan obtained from the three countries. It was also true that Pakistani government did not want to know what was going on as long as A.Q. Khan continued delivering on his promises. Two lessons learned are discovering the network did not kill it, and the A.Q. Khan network is unique.

Venkat K and WW Wakeland. 2006. "An Agent-Based Model of Trade with Distance-Based Transaction Cost." In Proceedings of the Summer Computer Simulation Conference (SCSC'06), The Society for Modeling and Simulation International, July 31-August 2, 2006, Calgary, Canada.

Utility: Moderate. Generally informative about implementation of a simple, geographical trading model but lacks necessary detail.

Theme: Venkat and Wakeland (2006) describe an application of agent-based modeling to investigate the effect of a distance-based transaction cost on material trade (not information exchange). Using agentbased computational economics to investigate two different initial allocations of goods among traders, they found that a geographically skewed initial allocation of goods performs poorly, while a more uniform initial distribution responds in a highly resilient way as the transaction cost is varied. 



\section{Distribution}

No. of

Copies

\# Name

Organization

Address

City, State and ZIP Code

\# Organization

Address

City, State and ZIP Code

Name

Name

Name

Name

Name (\#)

\# Name

Organization

Address

City, State and ZIP Code
No. of

Copies

\# Foreign Distribution

\# Name

Organization

Address

Address line 2

COUNTRY

\# Local Distribution

Pacific Northwest National Laboratory

Name

Name

Name

Name

Name
Mailstop

Mailstop

Mailstop

Mailstop

(PDF) 




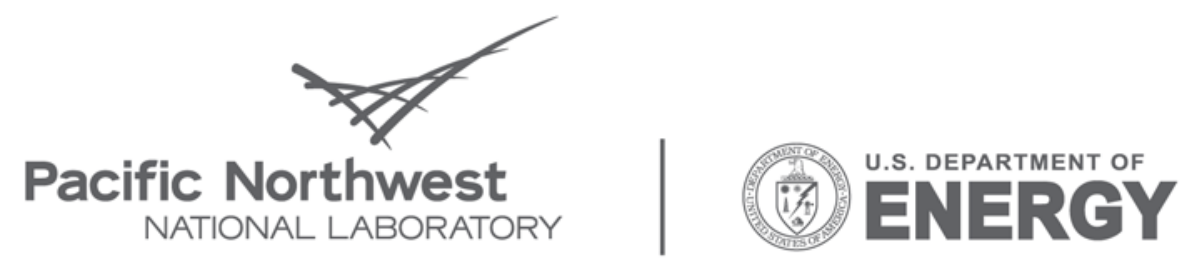

Proudly Operated by Battelle Since 1965

902 Battelle Boulevard

P.O. Box 999

Richland, WA 99352

1-888-375-PNNL (7665)

www.pnl.gov 